\title{
Apigetrin attenuates high fat diet-induced intestinal inflammation and nonalcoholic fatty liver disease (NAFLD) process
}

\author{
Zhi Liu' ${ }^{1}$, Dan-Dan Li ${ }^{1}$, Yi Li ${ }^{1}$ and Li-Li Zhu ${ }^{1}$ \\ ${ }^{1}$ Department of Traditional Chinese Medicine, Huai'an First People's Hospital, Nanjing Medical University, Huai'an 223300, \\ China
}

Correspondence to: Zhi Liu, email: liuzhi_tcm000@qq.com

Keywords: NAFLD; intestinal; apigetrin; oxidative stress; inflammation

Received: August 23, $2017 \quad$ Accepted: November 17, $2017 \quad$ Published: December 21, 2017

Copyright: Liu et al. This is an open-access article distributed under the terms of the Creative Commons Attribution License 3.0 (CC BY 3.0), which permits unrestricted use, distribution, and reproduction in any medium, provided the original author and source are credited.

\section{ABSTRACT}

Obesity and non-alcoholic fatty liver disease (NAFLD) are characterized by abnormal gut inflammation, and microbiota. Apigetrin (AGT), a flavonoid isolated from various herbal medicines such as Matricaria chamomilla and Scutellaria baicalensis Georgi, has a number of beneficial health effects, including anti-inflammatory and anti-oxidative bioactivities. In the present study, we attempted to explore the metabolic impact of AGT on high fat diet (HFD)-induced NAFLD and to investigate the consequent anti-diabetic effects associated with gut microbiota. C57BL/6J mice were fed with normal diet (ND) or HFD. And the mice with HFD were gavaged daily with or without AGT for $\mathbf{5 6}$ days. The gut microbiota composition was measured using 16s rRNA gene sequences. The results indicated that AGT reduced the weight gain, visceral and subcutaneous fat of HFD-feeding mice. AGT administration increased insulin sensitivity as evidenced by the improved insulin tolerance. AGT treatment also reduced liver weight and triglyceride (TG) accumulation, associated with the blunted hepatic oxidative stress and inflammation. Further, AGT administration could lower serum lipopolysaccharide (LPS) levels, intestinal glucose uptake, TG content, as well as prevent intestinal inflammation and oxidative stress. AGT decreased the secretion of pro-inflammatory cytokines, including tumor necrosis factor-a (TNF-a), interleukin (IL)-6 and IL-1 $\beta$, by inactivating nuclear factor-KB (NF-KB) pathway; and increased the levels of anti-oxidants, such as superoxide dismutase (SOD), heme oxygenase-1 (HO-1) and nuclear factor erythroid 2-related factor 2 ( Nrf-2). Of note, AGT reduced the intestinal bacterial overgrowth. Further more, the anti-oxidant and anti-inflammatory effects of AGT were confirmed in LPS- and fructose-stimulated cells in vitro. The results above indicated that AGT showed beneficial metabolic effects to attenuate HFD-induced NAFLD and intestinal injury.

\section{INTRODUCTION}

Obesity is a major health issue in recent decades [1]. Obesity could cause a substantially higher risk of developing features of the metabolic syndrome, including type 2 diabetes, dyslipidemia, hypertension, coronary heart disease, and non-alcoholic fatty liver disease (NAFLD), and even colon cancer [2-5]. The caloric restriction significantly attenuates obesity and NAFLD incidences, type-2-diabetes and cardiovascular disease in primates, rodents and humans $[6,7]$. The food intake and appetite are a complex physiologic process, regulating a variety of hormones and signals. The impairment of these appetiterelated molecules and associated signaling pathways leads to severe obesity $[8,9]$. The findings exhibited a prominent role for excessive food intake in modulating the obesity and associated diseases [10].

NAFLD is the most common etiology of chronic liver disease in developed (or /Western industrialized) countries. As the hepatic manifestation of the metabolic 
syndrome, NAFLD comprises a spectrum of liver diseases, including benign steatosis, steatohepatitis, cirrhosis and even hepatocellular carcinoma ultimately $[11,12]$. The pathophysiology of NAFLD involves gut-derived microbial components, lipotoxicity, oxidative stress and inflammation, which might be observed in the liver, but might be also originated from other tissues such as the gastrointestinal tract [13-15].

Obesity is tightly connected with chronic, low-grade systemic inflammation [16]. What's more, the intestinal epithelium, accompanied with its colonising bacteria, presents a first site of interactions between the diet and the host immune system. Such an interaction could influence the composition of the gut microbiota, affecting the gut homeostasis and the intestinal permeability [17, 18]. Thus, the intestine and its microbial composition are a potential source of pro-inflammatory molecules, which could influence the body metabolism, an early event that influence the obesity $[19,20]$. Accumulating evidences have indicated that gut microbiota plays an essential role in regulating energy homeostasis via meditation of oxidative stress, inflammatory response and glucose metabolism [21]. LPS is a potent inducer of inflammation, contributing to the onset and the progression of inflammatory response and associated metabolic disease, including NAFLD, revealing a key role for the intestinal microbiota as an orchestrator of the gut-liver axis [22, 23]. As indicated before, high-fat diet (HFD) could reshape the gut microbiota, influencing the pathogenesis of obesitycaused metabolic diseases [24]. Though numerous studies have been performed to investigate the complex pathophysiology of the metabolic disorders, NAFLD and disturbance of gut microbiota-induced disease have grown to pandemic proportions, thus promoting the investigation for new and effective therapeutic strategies.

Flavonoids have been widely investigated for their anti-inflammatory, anti-cancer, and anti-oxidant effects [25-27]. Apigetrin (AGT, Figure 1A), as a type of flavonoid, is isolated from various herbal medicines, such as Scutellaria baicalensis Georgi, Teucrium gnaphalodes, Matricaria chamomilla, and Stachys tibetica Vatke. AGT has various bioactivities, including anti-inflammatory response and anti-oxidative stress [28-30]. However, its effects on HFD-induced NAFLD and disturbance of gutmicrobiota are little to be known. Hence, we attempted to explore the metabolic role of AGT in NAFLD and gut microbiota in high fat diet-feeding mice.

\section{RESULTS}

\section{The effects of apigetrin on HFD-induced obesity}

As depicted in Figure 1B and 1C, HFD feeding induced higher body weight compared to the normal diet (ND)-feeding mice, while being reduced by AGT administration in a dose-dependent manner. However, there was no significant difference was observed in daily food intake in each group of mice (Figure 1D). In addition, the body weight gain was also accompanied with increased visceral and subcutaneous fat in HFD group of mice. And AGT-treated mice showed reduced mass of visceral and subcutaneous fat, further indicating the preventative effects of AGT on the body weight gain (Figure 1E). Furthermore, AGT improved the glucose intolerance and insulin resistance in HFD-induced mice (Figure $1 \mathrm{~F}$ and $1 G)$. AGT administration also led to greater goblet cell density in the ileum than was found in HFD-fed mice (Figure 1H).

\section{The effects of apigetrin on serum, liver and adipose tissue lipid profiles}

AGT treatment reduced serum TG and TC levels while concomitantly lowering liver weight and hepatic TG accumulation in HFD-fed mice (Figure 2A and 2B). H\&E staining also elucidated that extremely higher steatosis score, and hepatocyte ballooning scores was induced in HFD-treated mice, and consequently, the NAFLD activity score was increased compared to the ND group. Notably, the process was reversed by AGT dose-dependently. In addition, the number of oil red-stained cells in liver tissue sections was significantly reduced by AGT compared to the HFD group (Figure 2C). Similarly, HFD caused higher serum ALT and AST levels in mice with HFD diet, which was markedly decreased by AGT (Figure 2D). Importantly, the immunohistochemical analysis of SOD1 and TNF- $\alpha$ staining in hepatic tissue given the evidence by which oxidative stress and inflammation were involved in HFD-induced liver injury, which were inhibited by AGT administration (Figure 2E). Moreover, compared to the ND group, the mean adipocyte diameter was dramatically enhanced by HFD induction, while being dose-dependently reduced by AGT (Figure 2F).

\section{Apigetrin inhibits oxidative stress and inflammatory response in HFD-induced liver tissue samples}

In addition, AGT down-regulated the liver oxidative stress as evidenced by an induction of SOD and GPX activities, and by the reduction of MDA in the liver tissue samples of mice (Figure 3A). 4-hydroxynonenal or 4-HNE is a reactive $\alpha, \beta$-unsaturated aldehyde species generated during conditions of oxidative stress and peroxidation of polyunsaturated fatty acids [31]. Figure 3B indicated that AGT decreased the over-expression of 4-HNE triggered by HFD. Inflammatory response was also induced by HFD, along with the elevated secretion of pro-inflammatory cytokines, including TNF- $\alpha$, IL- 6 and IL-1 $\beta$, which was significantly alleviated by AGT (Figure 3C). Following, western blot analysis indicated that SOD1, HO-1 and Nrf2 protein levels were highly induced by AGT in HFD- 
treated mice, which was comparable to HFD group (Figure 3D). In contrast, Figure 3C indicated that HFD feeding caused the stronger expression of $\mathrm{p}-\mathrm{NF}-\kappa \mathrm{B}$, as well as an increased tendency of TNF- $\alpha$ and IL-1 $\beta$. Of note, AGT dose-dependently reduced the protein expression levels of these molecules (Figure 3E). Together, the data above indicated that AGT showed anti-oxidant and antiinflammatory effects on HFD-induced NAFLD.

\section{The effects of apigetrin on intestinal profile}

Furthermore, intestinal dysbiosis is linked to obesity and obesity-related NAFLD [32]. As shown in Figure 4A and 4B, HFD feeding resulted in longer intestinal length and higher intestinal weight, which were dramatically reduced by AGT administration. And consistently, high fat diet caused higher total length compared to the normal diet feeding mice. And AGT at the highest concentration reduced the total length of intestine (Supplementary Figure 1). Moreover, results suggested that the intestinal glucose up-take of the jejunal rings was markedly increased in HFD-treated mice compared to the ND group.
Consistently, AGT could reduce the up-take of glucose (Figure 4C). High fat diet-induced obesity could lead to metabolic endotoxemia, oxidative stress and inflammation, which is related to the enhanced intestinal permeability, as revealed by the elevated circulating LPS levels [33]. Our findings indicated that HFD induced higher levels of LPS in comparison to the ND group, which was downregulated by AGT in a dose-dependent manner (Figure 4D). And the process was along with the decreased TG levels in jejunum (Figure 4E). Glucose transporter type 2 (GLUT2) protein activates glucose transport from the intestinal lumen to the blood stream $[34,35]$. Here, we found that HFD induced high gene levels of GLUT2 in the jejunum of mice, which was reduced by AGT dosedependently (Figure 4F). H\&E staining of the jejunum showed that the villi were lengthened by HFD feeding, and AGT markedly decreased the length of villi (Figure 4G). Furthermore, the immunofluorescent analysis indicated that oxidative stress and inflammatory response were involved in AGT-attenuated intestine injury induced by HFD. Figure 4H demonstrated that HFD decreased SOD1 expressions, while increased TNF- $\alpha$ levels, which

A

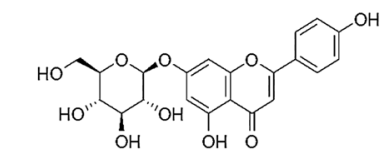

$\mathrm{B}$
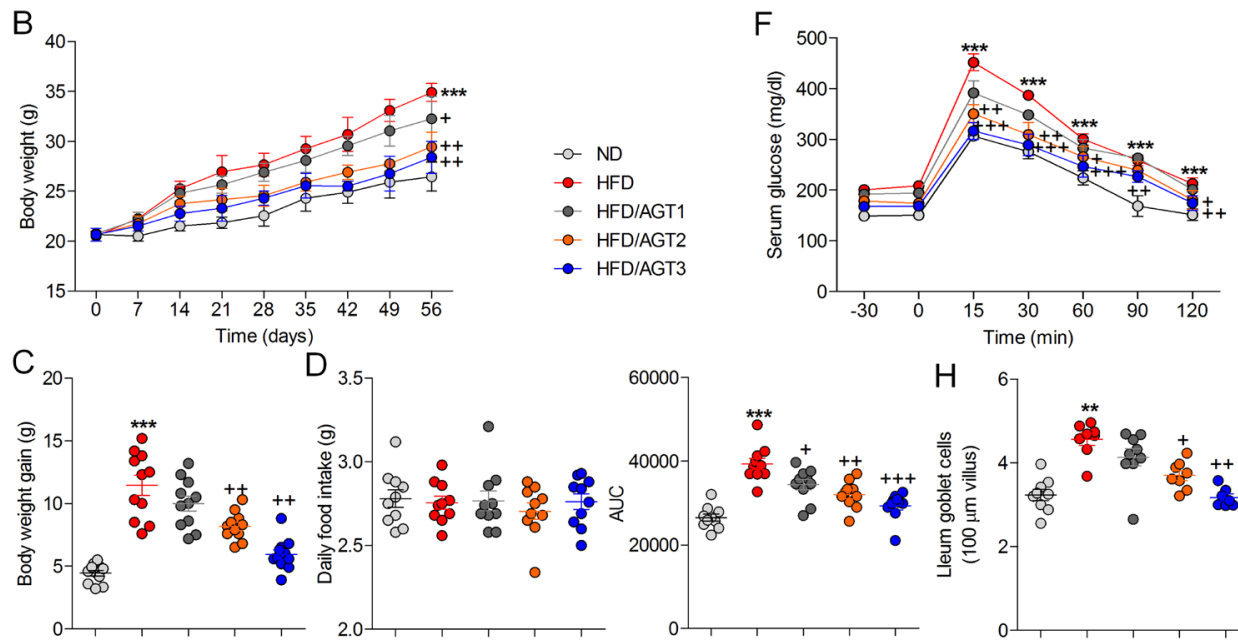

$-0-$ ND
$\rightarrow$ HFD

- HFD/AGT1

- HFDIAGT2

- HFD/AGT3
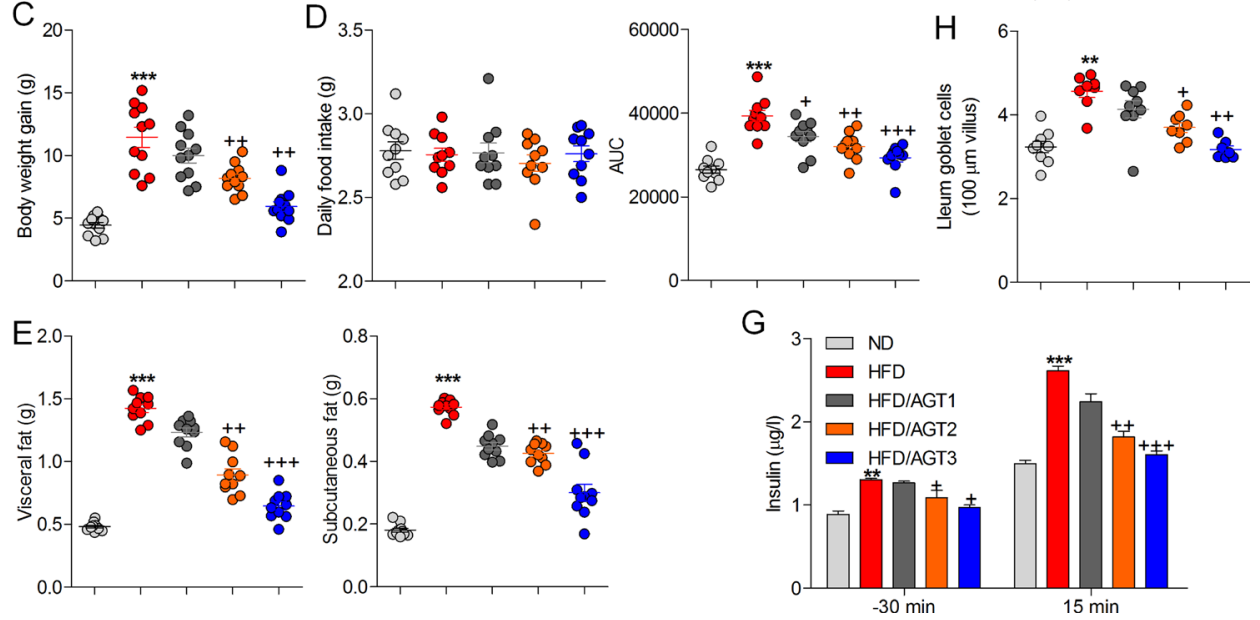

Figure 1: The effects of apigetrin on high-fat diet-induced obesity. (A) The chemical structure of apigetrin (AGT). (B) The weight gain curves. (C) The total weight gain. (D) The daily food intake in each mouse. (E) The visceral fat and subcutaneous fat were measured. (F) The plasma glucose (mg/dl) profile and the mean area under the curve (AUC) were calculated using OGTT analysis. (G) Serum insulin $(\mu \mathrm{g} / \mathrm{l})$ determined $30 \mathrm{~min}$ before and $15 \mathrm{~min}$ after glucose administration during the OGTT. (H) Ileum goblet cell density was evaluated. Data are represented as mean \pm S.E.M. $\left(n=8-10\right.$ /group). ${ }^{* *} P<0.01,{ }^{* * *} P<0.001$ versus the ND group; ${ }^{+} P<0.05,{ }^{++} P<0.01$ and ${ }^{++} P<0.001$ versus the HFD group. 
were dose-dependently reversed by AGT administration in small intestine of mice.

\section{Apigetrin suppresses oxidative stress and inflammation in jejunum of mice}

Also, in this regard, AGT could attenuate HFDinduced oxidative stress in mice, as evidenced by the enhanced SOD activity, GPx activity and reduced MDA levels (Figure 5A). Further, RT-qPCR analysis suggested that HFD dramatically induced the over-expression of TNF- $\alpha$, IL-6 and IL-1 $\beta$ in jejunum from gene levels, while being down-regulated by AGT in a dose-dependent manner (Figure 5B). Finally, flow cytometry analysis indicated that HFD dramatically induced higher levels of monocytes, macrophages and dentric cells, which were dose-dependently reduced by AGT (Figure 5C).

Following, Nrf-2 pathway was explored using western blot analysis. As shown in Figure 6A, we found that HFD-caused lower levels of SOD1, HO-1 and Nrf2 were highly reversed by AGT, indicating the effects of AGT on anti-oxidative stress in jejunum of mice. Moreover, in intestine, we also found that 4-HNE was highly induced by HFD, which was suppressed in AGTtreated groups at higher concentrations (Figure 6B). In addition, the inflammatory pathway was also suppressed by AGT in HFD-treated mice, evidenced by the reduced $\mathrm{p}-\mathrm{NF}-\kappa \mathrm{B}, \mathrm{TNF}-\alpha$ and IL-1 $\beta$ (Figure 6C). Finally, the immunofluorescent analysis further indicated that AGT reduced $\mathrm{p}-\mathrm{NF}-\kappa \mathrm{B}$ in the jejunum tissue sections from
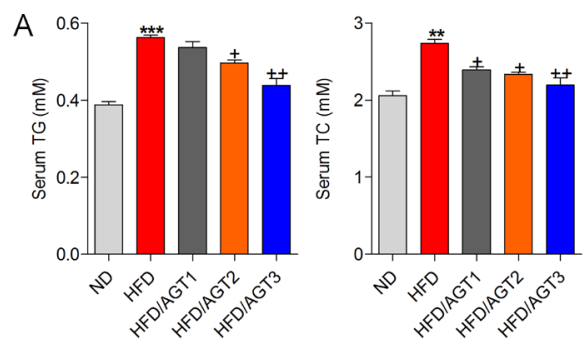

C
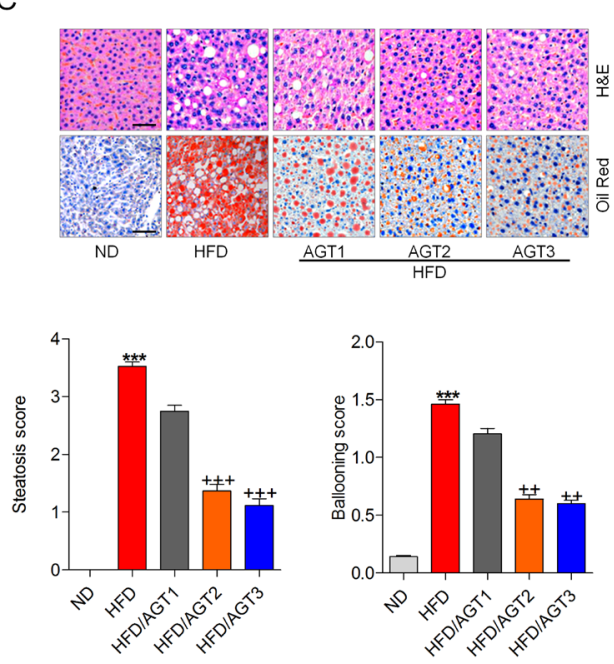

E

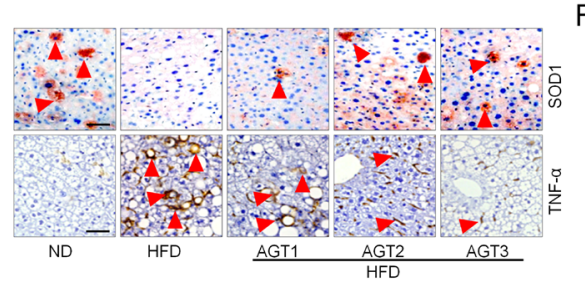

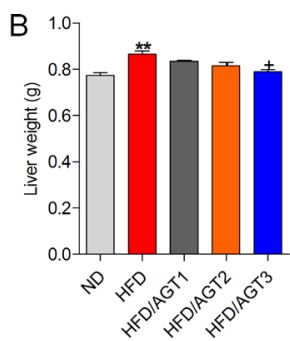
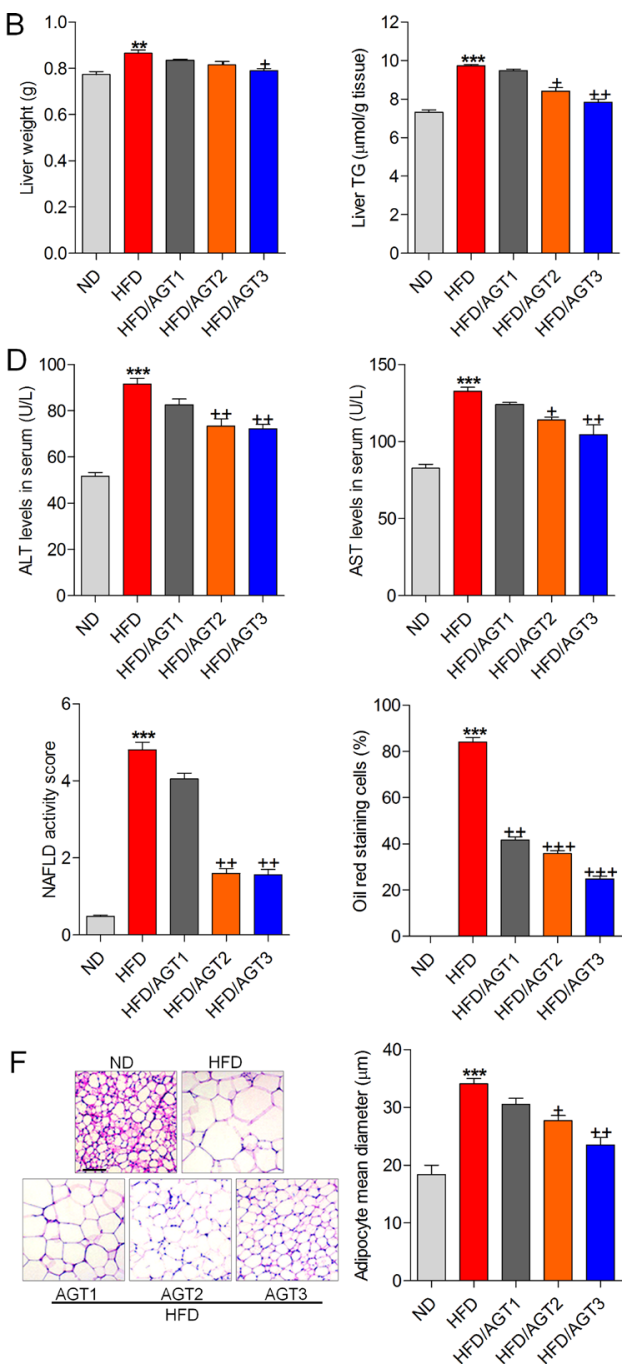

Figure 2: The effects of apigetrin on serum, liver and adipose tissue lipid profiles. (A) Serum TG and TC levels were examined. (B) Liver weight and TG levels were calculated. (C) H\&E staining and oil red staining were performed in liver tissue sections. The scale bar is $100 \mu \mathrm{m}$. Histopathological assessment of steatosis, hepatocyte ballooning and NAFLD activity score, as well as the oil red staining cells was presented in these groups. (D) Serum ALT and AST levels were tested. (E) The immunohistochemical analysis of SOD1 and TNF- $\alpha$ positive levels in liver tissue samples isolated from each group of mice. The red arrows represent SOD1 ${ }^{+}$or TNF- $\alpha^{+}$cells. The scale bar is $100 \mu \mathrm{m}$. (F) H\&E stained-pictures of subcutaneous adipose tissue deposits were displayed and the adipocyte diameter was quantified. The scale bar is $50 \mu \mathrm{m}$. Data are represented as mean \pm S.E.M. $\left(n=8-10\right.$ /group). ${ }^{* *} P<0.01,{ }^{* * *} P<0.001$ versus the ND group; ${ }^{+} P<0.05,{ }^{++} P<0.01$ and ${ }^{+++} P<0.001$ versus the HFD group. 
mice with HFD treatment (Figure 6D). The findings above indicated that AGT could attenuate the oxidative stress and inflammatory response in HFD-induced intestine.

\section{Apigetrin blocks intestinal bacterial overgrowth}

In this regard, the role of AGT in regulating the growth of intestinal bacterial was investigated. As shown in Figure 7A, HFD feeding enhanced the growth of intestinal bacteria, elevated firmicutes and reduced the bacteroidetes, and the processes were reversed by AGT. Further, Figure 7B indicated that HFD induced lower proportion of Akkermansia in comparison to the ND group, which was up-regulated by AGT in a dosedependent manner; no significant difference was observed in the alterations of Lactobacillus in cecum of mice treated neither with or without HFD or AGT.

\section{Apigetrin impedes oxidative stress and inflammation in colonic epithelial cells in vitro}

Here, in this part, the in vitro experiments were performed to calculate the effects of AGT on oxidative stress and inflammation in LPS-treated colonic epithelial cell line of NCM460. First, MTT analysis indicated that there was no cytotoxicity of AGT to cells treated as the described (Figure 8A). Following, the cells were exposed to LPS at the indicated time, and western blot analysis indicated that LPS-caused the protein expressions of TNF- $\alpha$, IL-6 and IL-1 $\beta$ in a time-dependent manner
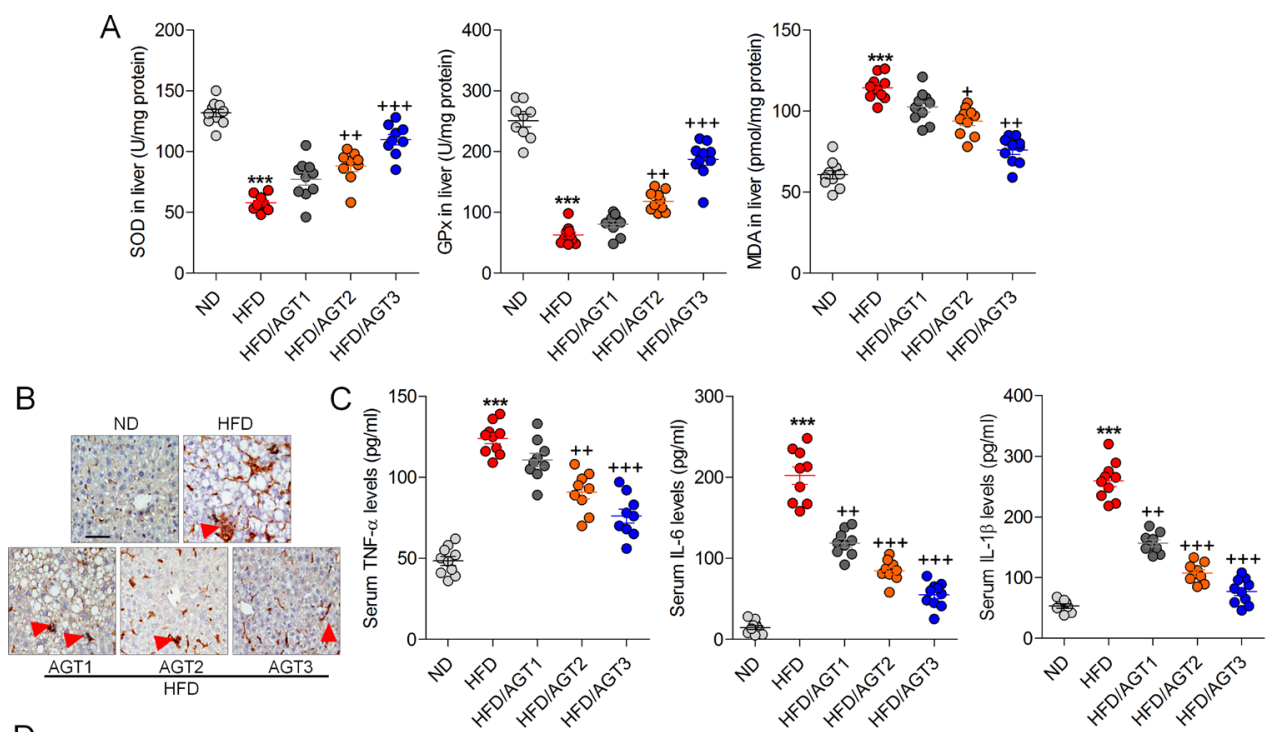

D
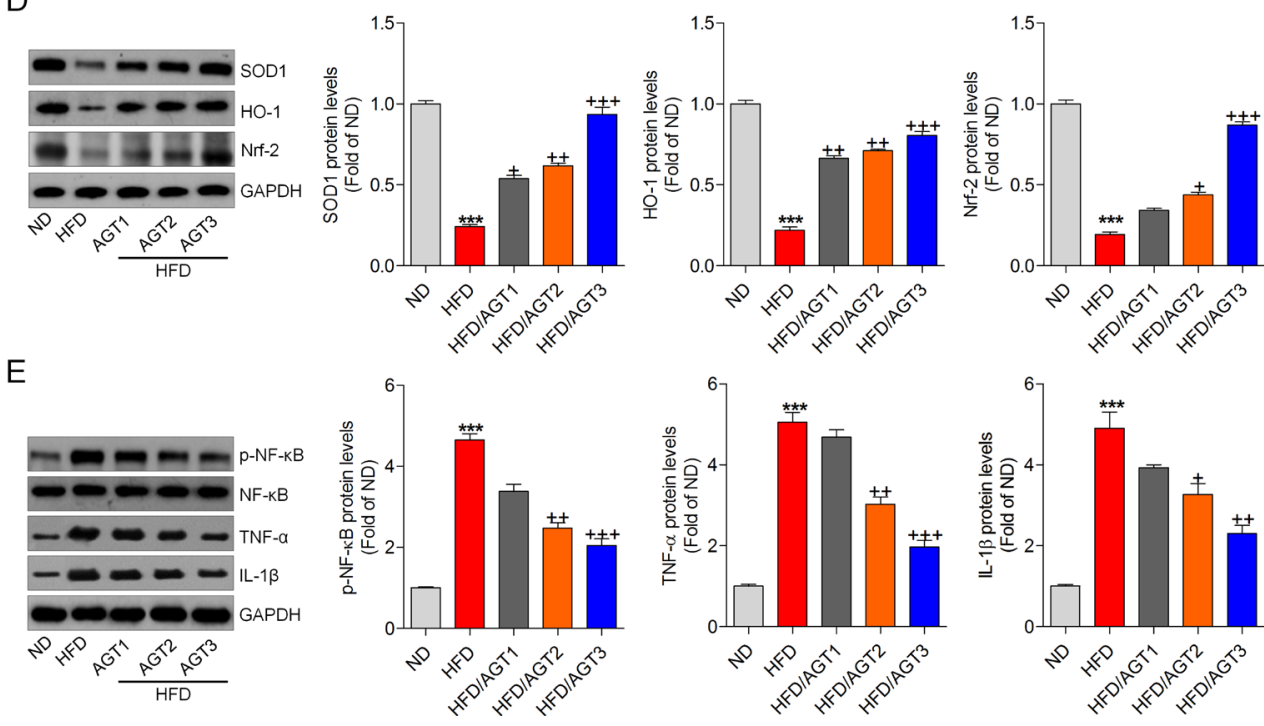

Figure 3: Apigetrin inhibits oxidative stress and inflammatory response in high fat diet-induced liver tissue samples. (A) Liver SOD, GPx and MDA were measured. (B) Immunohistochemical analysis of 4-HNE in liver tissue sections. The red arrows represent $4-\mathrm{HNE}^{+}$cells. The scale bar is $100 \mu \mathrm{m}$. (C) Pro-inflammatory cytokines of TNF- $\alpha$, IL-6 and IL-1 $\beta$ in serum. (D) Western blot analysis of SOD1, HO-1 and Nrf-2 in liver tissue samples. (E) Western blot analysis of p-NF- $\kappa \mathrm{B}, \mathrm{TNF}-\alpha$ and IL-1 $\beta$. Data are represented as mean \pm S.E.M. $\left(n=8-10\right.$ /group). ${ }^{* * *} P<0.001$ versus the ND group $;{ }^{+} P<0.05,{ }^{++} P<0.01$ and ${ }^{+++} P<0.001$ versus the HFD group. 
(Figure 8B). And then, NCM460 cells were incubated with LPS for $24 \mathrm{~h}$ with or without AGT at the indicated doses. LPS down-regulated SOD1, HO-1 and Nrf-2 expression levels, which were reversed by AGT in a dose-dependent manner (Figure 8C). Additionally, p-NF- $\kappa \mathrm{B}, \mathrm{TNF}-\alpha$ and IL-1 $\beta$ were highly induced by LPS using western blot analysis, whereas being reduced by AGT (Figure 9A). Consistently, $\mathrm{p}-\mathrm{NF}-\kappa \mathrm{B}$ levels stimulated by LPS were also alleviated by AGT (Figure 9B). Further, the cells were also treated with fructose to confirm the effects of AGT on suppressing oxidative stress and inflammation. As shown in Figure 10A, $5 \mathrm{mM}$ fructose induced higher gene levels of TNF- $\alpha$, IL- 6 and IL-1 $\beta$, and the levels of these molecules were highly reduced by AGT in a dosedependent manner. In contrast, Fru-reduced SOD1, HO-1 and Nrf-2 mRNA levels was improved by AGT (Figure 10B). In the end, western blot analysis indicated that the phosphorylation of $\mathrm{NF}-\kappa \mathrm{B}$ was markedly induced by Fru, and was decreased by AGT in Fru-incubated cells
(Figure 10C). The findings above confirmed that in vitro, AGT showed anti-oxidant and anti-inflammatory effects both in LPS- and fructose-stimulated cells.

\section{DISCUSSION}

Accumulating studies indicated that a large number of natural compounds have various bioactivities, which are inversely associated with some features of the metabolic syndrome, contributing to the reduction of obesity, type 2 diabetes and NAFLD [36, 37]. Oxidative stress, and inflammatory response are intensively involved in the development of obesity, and NAFLD [15, 16, 38]. Given the effects of AGT on suppressing oxidative stress and inflammation in microglia and lung injury, it was explored in our study to reveal its effects on the treatment of NAFLD and the improvement of gut microbiota dysbiosis. In the present study, AGT administration reduced HFDcaused body weight gain, decreased visceral adiposity
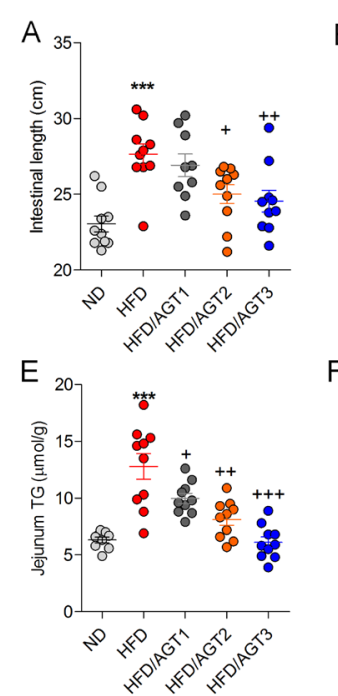

F
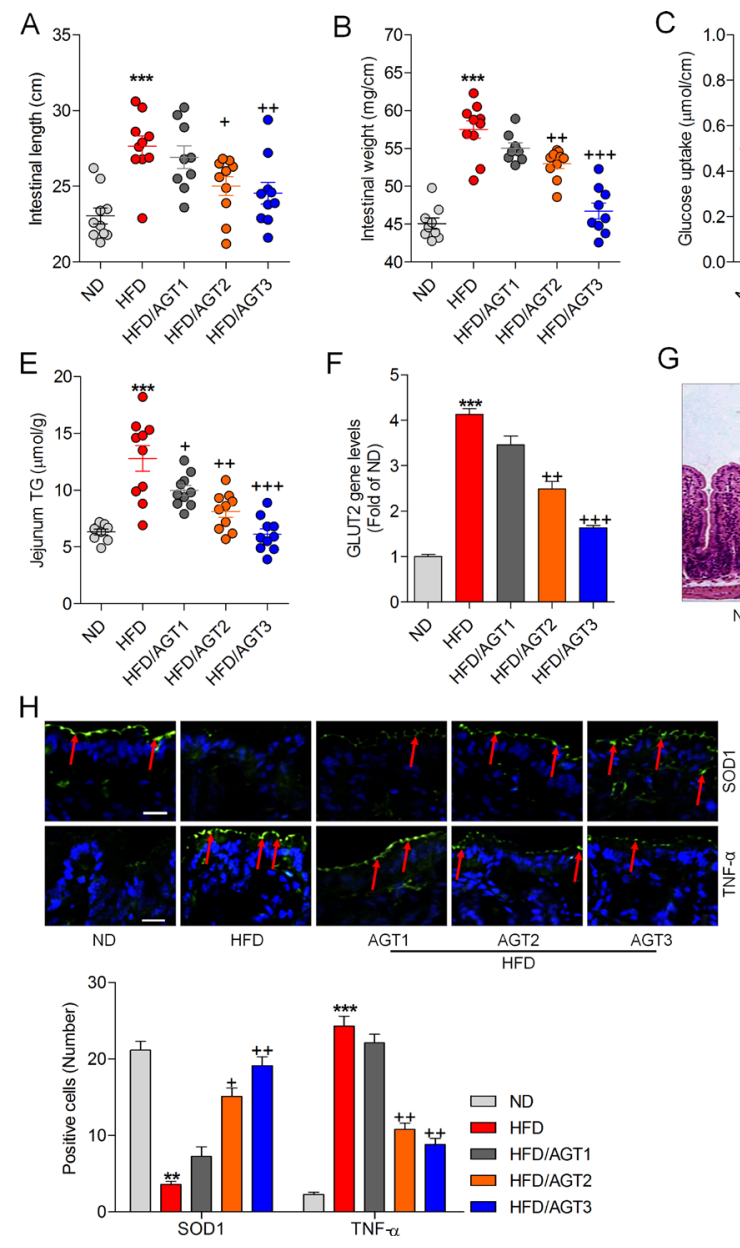
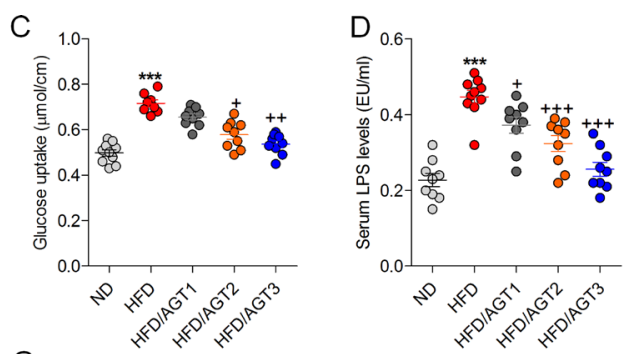

G
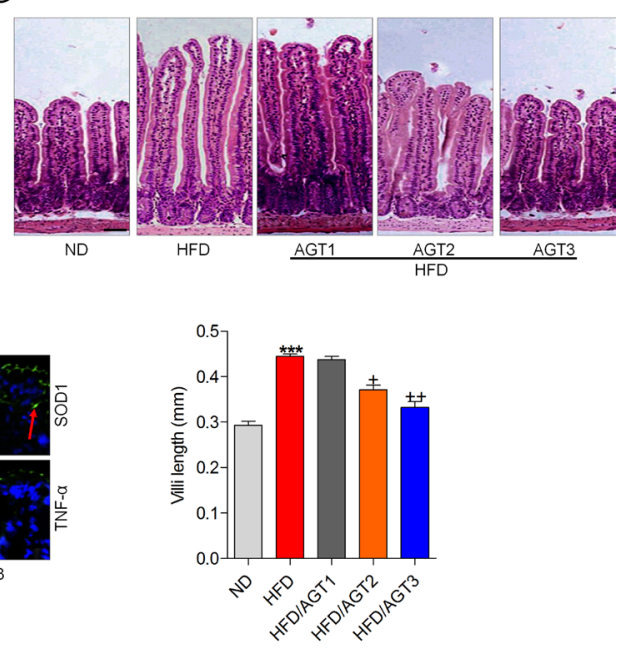
and subcutaneous fat of HFD-fed mice. AGT also downregulated liver weight and TG accumulation, which was linked to the blunted oxidative stress and inflammation in liver. AGT treatment enhanced the insulin sensitivity, as proved by the attenuated insulin tolerance. Furthermore, AGT treatment could reduce serum LPS levels, glucose uptake, TG levels and inhibit intestinal inflammation as well as oxidative stress triggered by HFD. AGT reduced the releasing of pro-inflammatory cytokines, including TNF- $\alpha$, IL-6 and IL- $1 \beta$, through inactivating NF- $\kappa$ B pathway; and increased the anti-oxidants, such as SOD, HO-1 and Nrf-2. Of note, AGT reduced the intestinal bacterial over-growth. Additionally, the anti-oxidant and anti-inflammatory effects of AGT were further confirmed in LPS- and fructose-stimulated cells in vitro. These results support the evidence that AGT can reduce body fat and be used as a dietary feed supplement in animals and patients. But it is warned that AGT should be used with caution in normal individuals.

TG accumulation is a key measure of hepatic steatosis, which is combined with oxidative stress and inflammatory response, contributing to the progression of NAFLD, a most important reason of liver disease in the world [39]. NAFLD is usually observed in the setting of insulin resistance and obesity [40]. Similarly, in our study, insulin resistance induced by HFD was attenuated in AGT-treated groups, which was evidenced by OGTT analysis and reduced serum insulin levels, indicating that AGT improved the insulin sensitivity of animals. Further, serum TG and TC levels, liver TG contents as well as the higher number of oil-red-staining cells induced by HFD were dramatically reduced by AGT, demonstrating that
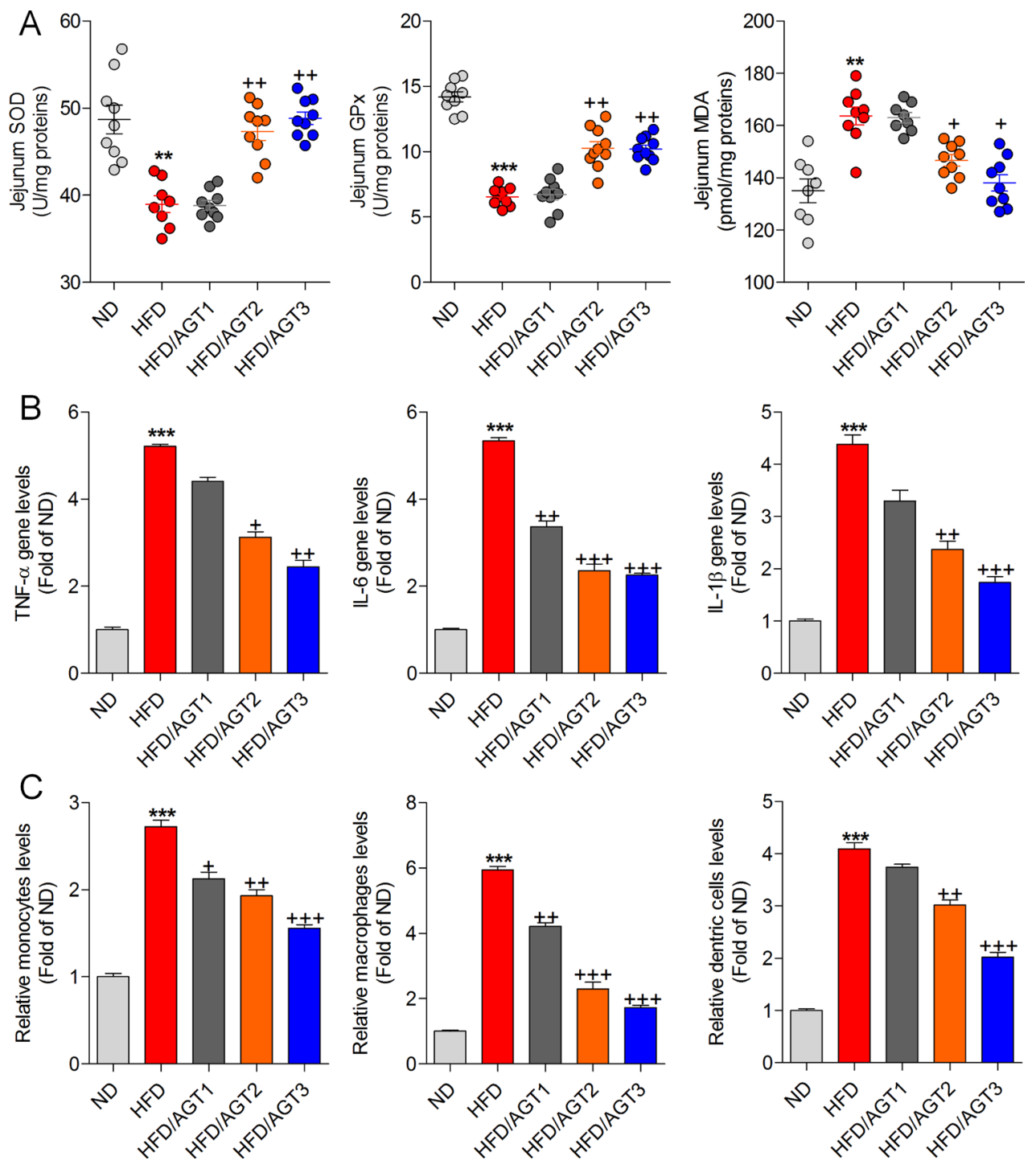

Figure 5: Apigetrin suppresses oxidative stress and inflammation in jejunum of mice. (A) SOD activity, GPx activity and MDA levels in jejunum were measured. (B) TNF- $\alpha$, IL-6 and IL-1 $\beta$ gene levels in jejunum. (C) Relative amount of inflammatory cells isolated from the jejunum was analyzed using flow cytometry. Data are represented as mean \pm S.E.M. $(n=8-10 /$ group $) .{ }^{* *} P<0.01,{ }^{* * *} P<$ 0.001 versus the ND group $;{ }^{+} P<0.05,{ }^{++} P<0.01$ and ${ }^{++} P<0.001$ versus the HFD group. 
AGT reduced lipid accumulation, thus alleviating NAFLD development. However, the possible molecular mechanism by which AGT alleviates lipid metabolism requires further research in future.

According to previous studies, oxidative stress and inflammation are highly involved during the pathogenesis of NAFLD $[11,13]$. In our study, AGT treatment enhanced the SOD activity, GPx activity and reduced the MDA levels, indicating that AGT potentiated the oxidant defense mechanisms, along with the improved Nrf-2/HO-1 pathway both in liver and intestine. Nrf-2 activation upregulates the expression of a group of functionally diverse cytoprotective proteins, including SOD and HO-1. SOD could remove the free radical species within cells [41, 42].
HO-1, one of the critical components in the endogenous antioxidant system of the body, is a stress-inducible ratelimiting enzyme in the metabolism of heme, releasing the carbon monoxide, bioactive molecules, and iron, which are involved in the defense and repair system of organism against oxidative stress [43-46].

$\mathrm{NF}-\kappa \mathrm{B}$ is a transcription factor, appearing to be the major intracellular signaling peptide, increasing the expression of endothelial adhesion molecules [47, 48]. While not activated, NF- $\kappa \mathrm{B}$ is bound to the nuclear factor$\kappa \mathrm{B}$ inhibitor $(\mathrm{I} \kappa \mathrm{B})$ and is retained in the cell cytoplasm. Once the cell is stimulated, I $\mathrm{B}$ is phosphorylated by specific kinases and degraded rapidly, subsequently releasing NF- $\kappa \mathrm{B}$. The released NF- $\kappa \mathrm{B}$ translocates to the
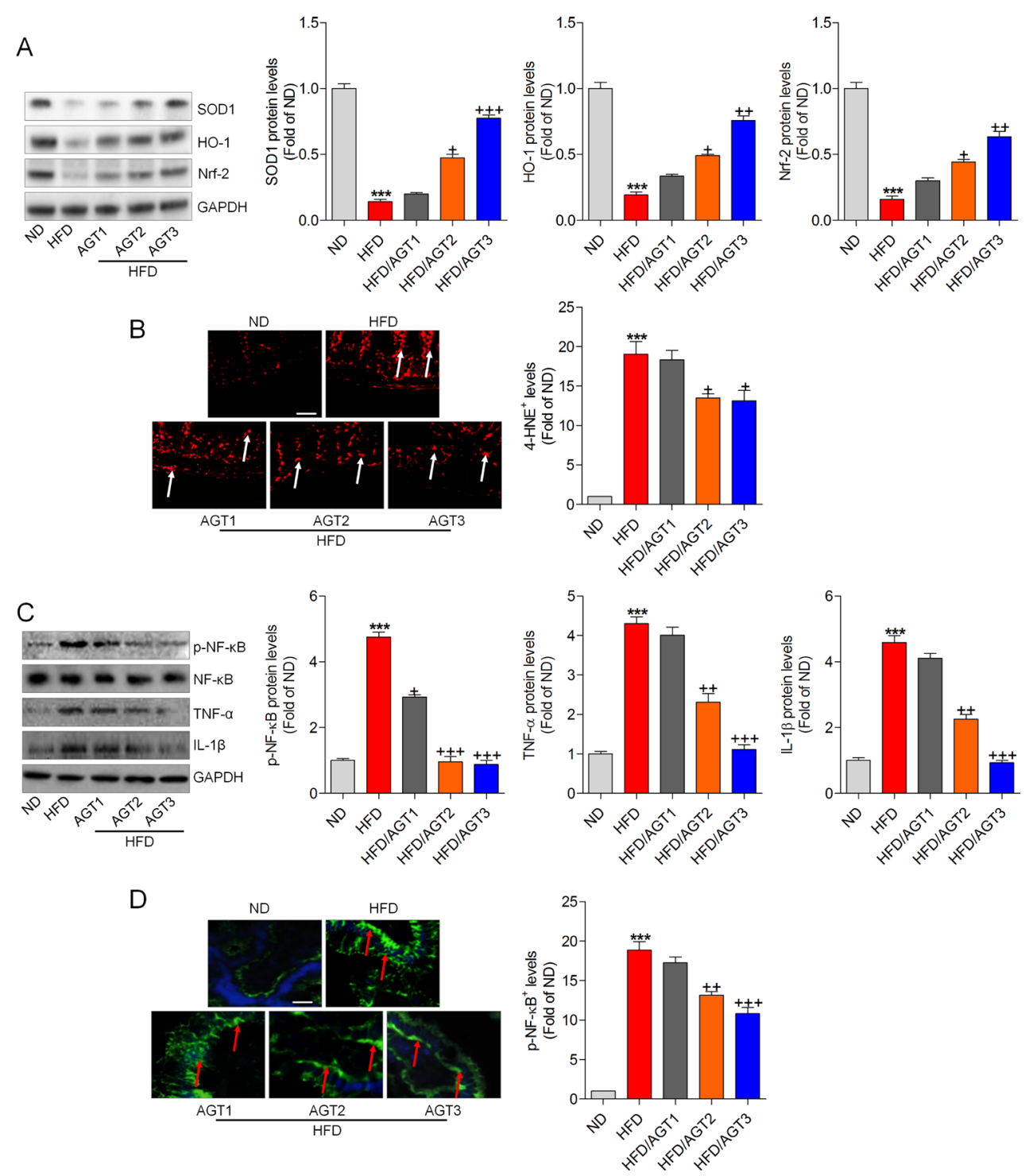

Figure 6: Apigetrin activates Nrf-2 pathway and inactivates NF-кB pathway. (A) Western blot analysis of SOD1, HO-1 and Nrf-2 in jejunum tissue samples. (B) Immunofluorescent analysis of 4-HNE in intestine tissue sections. The white arrows represent $4-\mathrm{HNE}^{+}$cells. The scale bar is $100 \mu \mathrm{m}$. (C) p-NF- $\kappa \mathrm{B}$, TNF- $\alpha$ and IL-1 $\beta$ protein levels were measured using western blot assays. (D) The immunofluorescent analysis of $\mathrm{p}-\mathrm{NF}-\mathrm{\kappa B}$ in jejunum tissue. The red arrows represent $\mathrm{p}-\mathrm{NF}-\kappa^{+} \mathrm{B}^{+}$cells. The scale bar is $100 \mu \mathrm{m}$. Data are represented as mean \pm S.E.M. $\left(n=8-10\right.$ /group). ${ }^{* * *} P<0.001$ versus the ND group; ${ }^{+} P<0.05,{ }^{++} P<0.01$ and ${ }^{+++} P<0.001$ versus the HFD group. 
nucleus, where it regulates the gene expression, including TNF- $\alpha$, IL- 6 and IL-1 $\beta[49,50]$. The process leads to the progression of inflammatory response, and contributes to inflammatory disease development, including NAFLD $[15,23,51]$. Consistently, we found that AGT downregulated the expression of these pro-inflammatory cytokines, accompanied with the inactivation of NF$\kappa \mathrm{B}$ both in liver tissue samples and intestinal segments. Further, LPS is derived from the gut microbiota, reaching the portal circulation, accessing the liver to influence the host metabolic physiology in essential ways [52, 53]. Accelerated levels of the circulating LPS in individuals with obesity have been suggested to be a result of high fatdiet-induced alterations in gut microbiota [54]. Moreover, metabolic endotoxemia, the increased circulating LPS after an obesogenic diet, is explained by the transport of LPS from the gut lumen through newly synthesized chylomicrons from the enterocytes responding to the high fat feeding and through a gut microbiota-dependent disruption of the gut barrier, therefore favoring the LPS leakage $[55,56]$. In line with previous studies, serum LPS levels induced by HFD were highly reduced by AGT. The reduced LPS levels might be accounted for the suppressed inflammatory response, which was likely associated with NF- $\mathrm{BB}$ inactivation through TLR4/ MyD88 pathway [57]. In vitro, we found that AGT exhibited anti-oxidant and anti-inflammatory effects on LPS- and fructose-stimulated cells by enhancing Nrf-2 expression and reducing $\mathrm{NF}-\kappa \mathrm{B}$ activation. Moreover, there was no significant difference in the cell viability of cells treated under different conditions, indicating its safety for application.

Furthermore, several studies have indicated that the gut microbiota has a causal role in the pathogenesis of obesity, as well as the NAFLD [17, 19, 58, 59]. As previously described, the altered gut microbiota composition and function contribute to the development of obesity in mice and its associated comorbidities in both mice and humans $[60,61]$. Our results showed that HFD feeding induced a dramatic shift in the gut microbiota of mice by increasing the proportion of Firmicutes and decreasing the proportion of Bacteroidetes. This dietinduced reshape in the microbial community of HFD-fed mice is a typical characteristic of obesity-driven dysbiosis and is in agreement with previous publications, which is considered to play a key role in the pathogenesis of obesity-induced metabolic diseases [62]. The disturbance of microbiota could lead to the activation of immune cells, including monocytes, macrophages and dendritic cells as the first line innate immune defense. Consistently, AGT reduced HFD-caused higher levels of monocytes, macrophages and dendritic cells, indicating the alleviated immune injury in mice with NAFLD. Akkermansia muciniphila, a mucin degrading bacterium, was a contributor to the maintenance of gut health and glucose homeostasis [17, 63-65]. Similarly, in our study we found
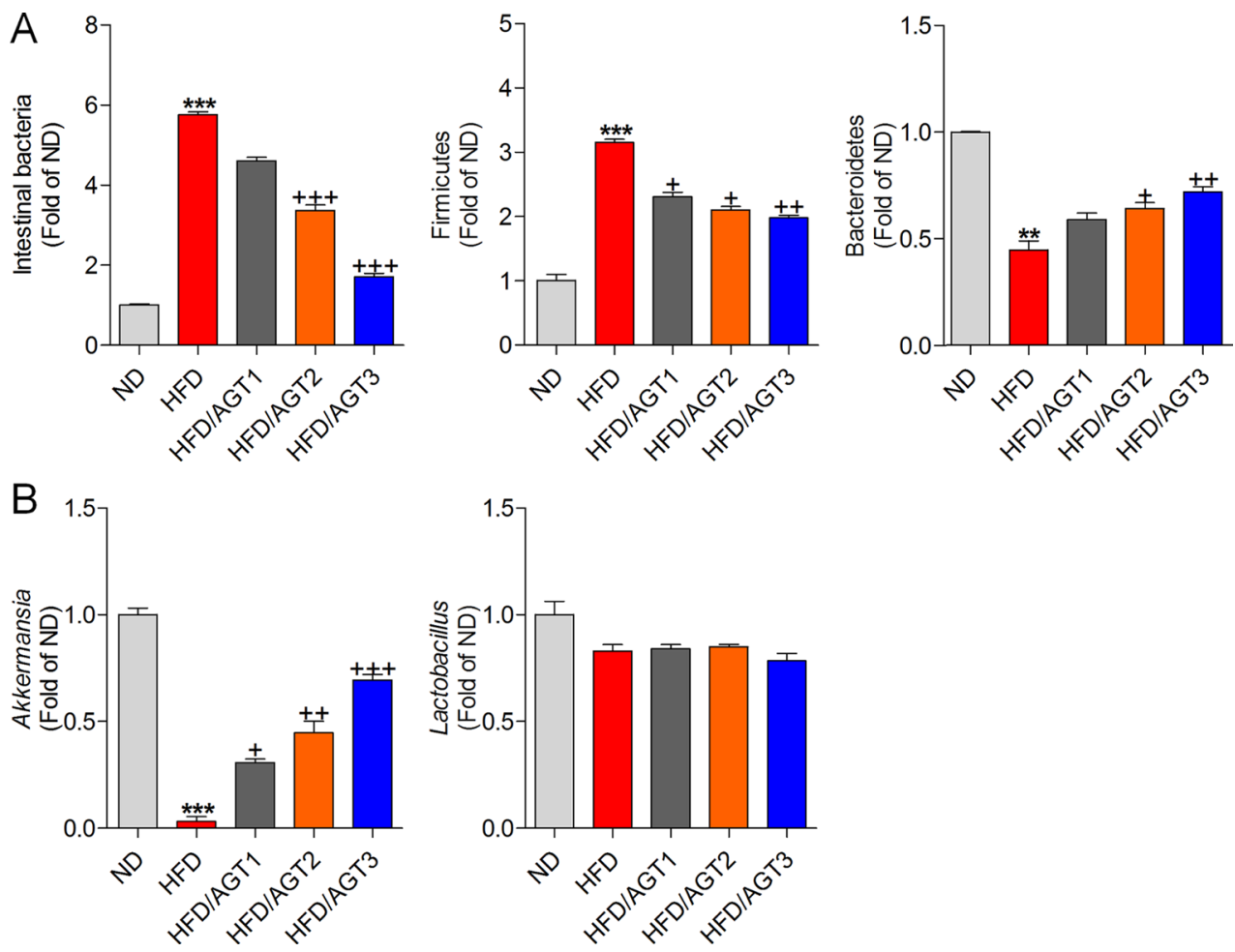

Figure 7: Apigetrin blocks intestinal bacterial overgrowth. (A) The total intestinal bacteria in cecum of mice, and the relative proportions of firmicutes, and bacteroidetes. (B) Relative proportions of Akkermansia and Lactobacillus in cecum of mice. Data are represented as mean \pm S.E.M. $\left(n=8\right.$-10/group). ${ }^{* *} P<0.01,{ }^{* * *} P<0.001$ versus the ND group $,{ }^{+} P<0.05,{ }^{++} P<0.01$ and ${ }^{+++} P<0.001$ versus the HFD group. 
that HFD induced lower levels of Akkermansia, which was reversed by AGT, thereby attenuating the disturbance of gut microbiota. However, data relating AGT to NAFLD, intestine injury and related gut microbiota are still limited, and cellular and molecular mechanisms remain elusive because of the lack of detailed experimental investigations. Thus detailed studies are warranted before any recommendations regarding the use of AGT in NAFLD can be made.

In conclusion, our findings suggested that AGT administration could protect from high fat diet-induced NAFLD in mice. The effect was related to the attenuation of the metabolic endotoxemia and intestinal inflammatory response. And HFD-caused disturbance of gut microbiota was also improved by AGT, which was a key in its protective effect (Figure 11). The results above indicated that AGT prevented NAFLD via a prebiotic role in gut microbiota. AGT supplementation might be considered as a therapy for NAFLD.

\section{MATERIALS AND METHODS}

\section{Reagents}

Apigetrin (purity > 98\%, CAS: 578-74-5) was purchased from Jianglai Bio (Shanghai, China). 3-(4, 5-dimethylthiazolyl-2-yl)-2, 5-diphenyltetrazolium bromide (MTT), Tween 20, 4'-6-diamidino-2-phenylindole
(DAPI) and dimethyl sulfoxide (DMSO) were obtained from KeyGen Biotech (Nanjing, China). LPS (Escherichia coli055:B5), M3 media and collagenase type VIII were purchased from Sigma Aldrich (USA). Fetal bovine serum (FBS), TRIzol Reagent and RPMI 1640 medium were purchased from Gibco (USA). Polyvinylidene fluoride membrane (PVDF) was obtained from Millipore (USA). Pacific Blue-labeled CD11b, PerCP-labeled CD11c, PE-labeled TNF $\alpha$, APC-labeled CD45.2, FITClabeled Lys6C, APC-labeled CD103, PECy7-labeled F4/80 were all purchased from eBiosciences (USA). Aspartate transaminase (AST), alanine Transaminase (ALT), triglyceride (TG), total cholesterol (TC), superoxide dismutase (SOD), glutathione peroxidase (GPx), and malondialdehyde (MDA) were obtained from Jiancheng Biotech Co., Ltd (Nanjing, China). The mouse insulin ELISA kits was obtained from Jiangsu ZeYu Biotechnology Co., Ltd. (Yancheng, China). ELISA kits of TNF- $\alpha$, IL- 6 , and IL- $1 \beta$ were purchased from the R\&D Systems Inc. (USA). The primary antibodies used in our study: anti-HO-1, anti-Nrf-2, anti-SOD1, anti-p-NF- $\kappa$ B, anti-TNF- $\alpha$, anti-IL-1 $\beta$, anti-NF- $\kappa$ B, anti-IL-6, anti-4 Hydroxynonenal (HNE) and anti-GAPDH were purchased from Abcam (USA) at 1:1000 or 1:500 dilution. M-MLV reverse transcriptase was purchased from Promega (USA). Sybr Green was obtained from Shanghai Rui Ann biotechnology limited company (China). TissueTekO.C.T. compound was obtained from Sakura Finetek

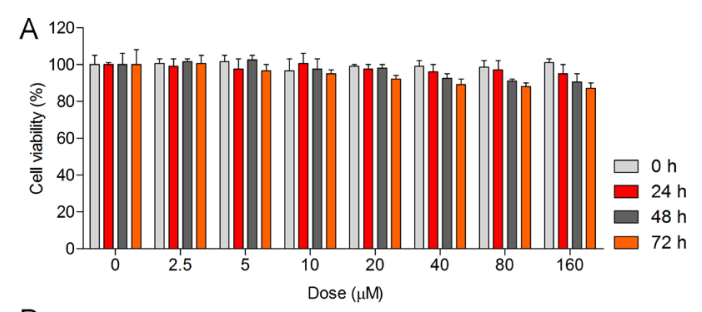

B
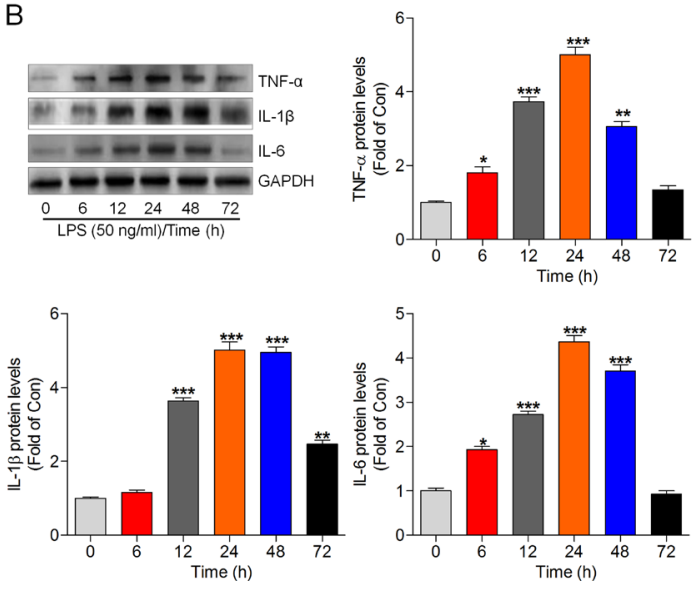

C
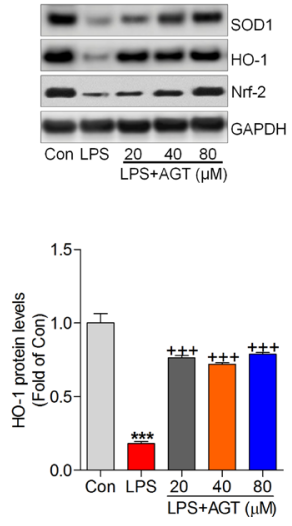
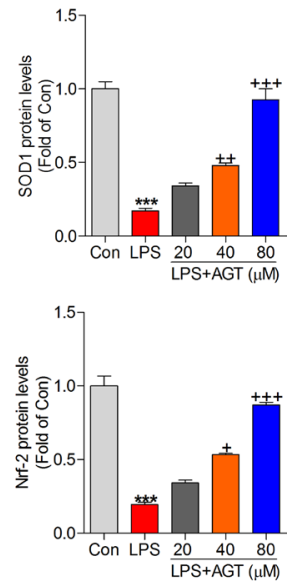

Figure 8: Apigetrin impedes oxidative stress in colonic epithelial cells in vitro. (A) The colonic epithelial cell line of NCM460 were treated with AGT $(0,2.5,5,10,20,40,80$, and $160 \mu \mathrm{M})$ for $0,24,48$ or $72 \mathrm{~h}$, followed by MTT analysis. (B) NCM460 cells were exposed to LPS (50 ng/ml) for 0, 6, 12, 24, 48 or $72 \mathrm{~h}$. And then, all cells were harvested for western blot analysis of TNF- $\alpha$, IL-6 and IL13. (C) NCM460 were incubated with $50 \mathrm{ng} / \mathrm{ml}$ LPS for $24 \mathrm{~h}$ in the absence or presence of AGT $(20,40$, or $80 \mu \mathrm{M})$. Data are represented as mean \pm S.E.M. $\left(n=6\right.$-8/group). ${ }^{*} P<0.05,{ }^{* *} P<0.01,{ }^{* * *} P<0.001$ versus the Con group; ${ }^{+} P<0.05,{ }^{++} P<0.01$ and ${ }^{+++} P<0.001$ versus the LPS group. 
USA Inc. (USA). Fructose was purchased from SanlandChem International Inc. (Xiamen, China).

\section{Animals and treatments}

75 male, 6 week-old, C57BL/6 mice (18-20 g) were purchased from Experimental Animal Center of Nanjing
Medical University (Nanjing, China). All mice were fed with drinking water, and housed in a temperature of 22 $\pm 2^{\circ} \mathrm{C}$ and relative humidity of $60 \pm 10 \%$ environment under $12 \mathrm{~h}$ light/dark cycles. The 75 animals were divided into 5 groups with 15 in each: (1) The normal diet fed-group (Normal diet: ND). (2) The high fat (HF) diet-feeding group (HFD). (3) $15 \mathrm{mg} / \mathrm{kg}$ AGT-treated
A
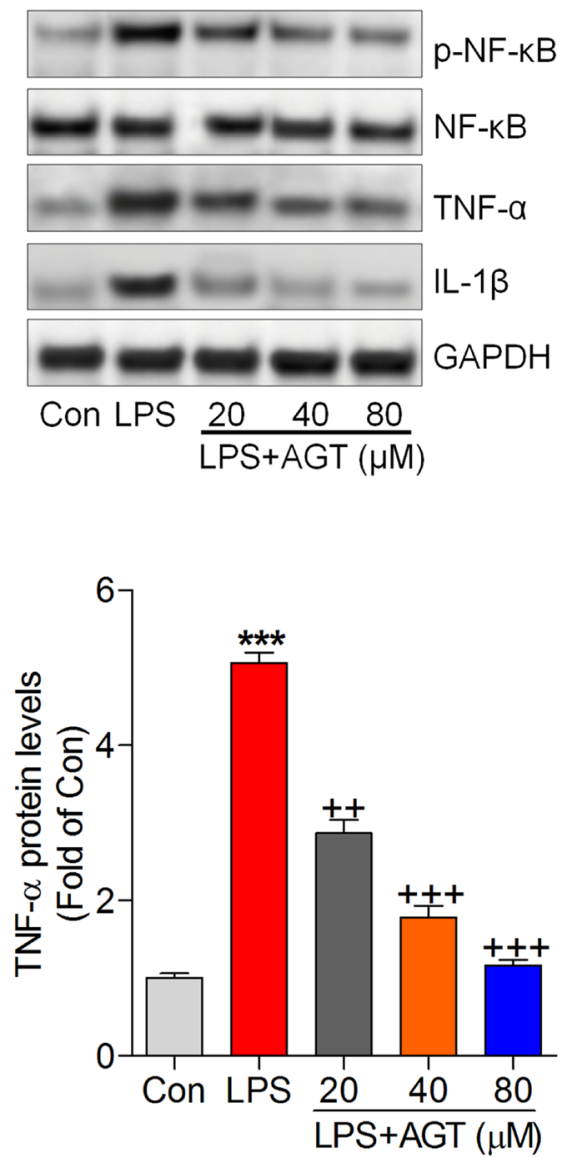

B
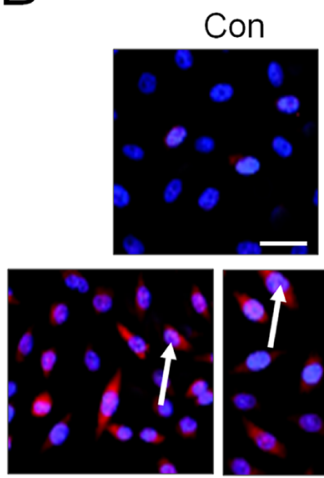

20

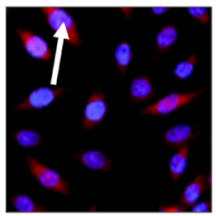

40
LPS
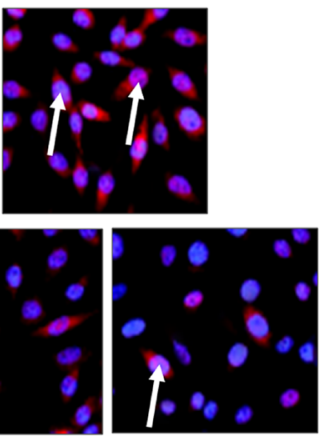

80

LPS+AGT $(\mu \mathrm{M})$
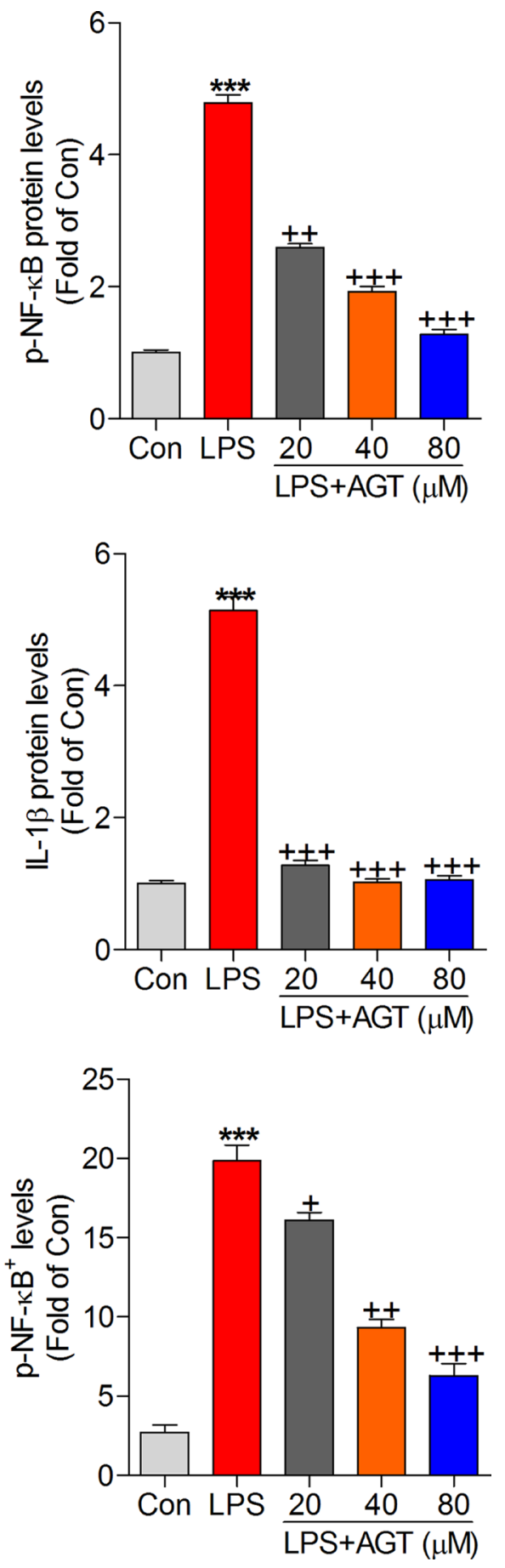

Figure 9: Apigetrin alleviates LPS-induced inflammation in cells. NCM460 were incubated with $50 \mathrm{ng} / \mathrm{ml} \mathrm{LPS}$ for $24 \mathrm{~h}$ with or without AGT at the indicated concentrations. (A) Western blot analysis of p-NF- $\kappa B$, TNF- $\alpha$ and IL-1 $\beta$. (B) Immunofluorescent analysis of p-NF- $\kappa \mathrm{B}$. The scale bar is $50 \mu \mathrm{m}$. Data are represented as mean \pm S.E.M. $\left(n=6-8 /\right.$ group). ${ }^{* * *} P<0.001$ versus the Con group; ${ }^{+} P<0.05$, ${ }^{++} P<0.01$ and ${ }^{++} P<0.001$ versus the LPS group. 
mice with HFD (AGT1). (4) $30 \mathrm{mg} / \mathrm{kg}$ AGT-treated mice with HFD (AGT2). (5) $60 \mathrm{mg} / \mathrm{kg}$ AGT-treated mice with HFD (AGT3) [29]. The high fat diet contained $60 \mathrm{kcal} \%$ Fat (Research Diets D12492, USA). AGT was dissolved in distilled water and given to mice via gavage. The mice given distilled water were used as control. 60 mice were fed with high fat diet with or without AGT for 8 weeks. During the process, the body weight of animals
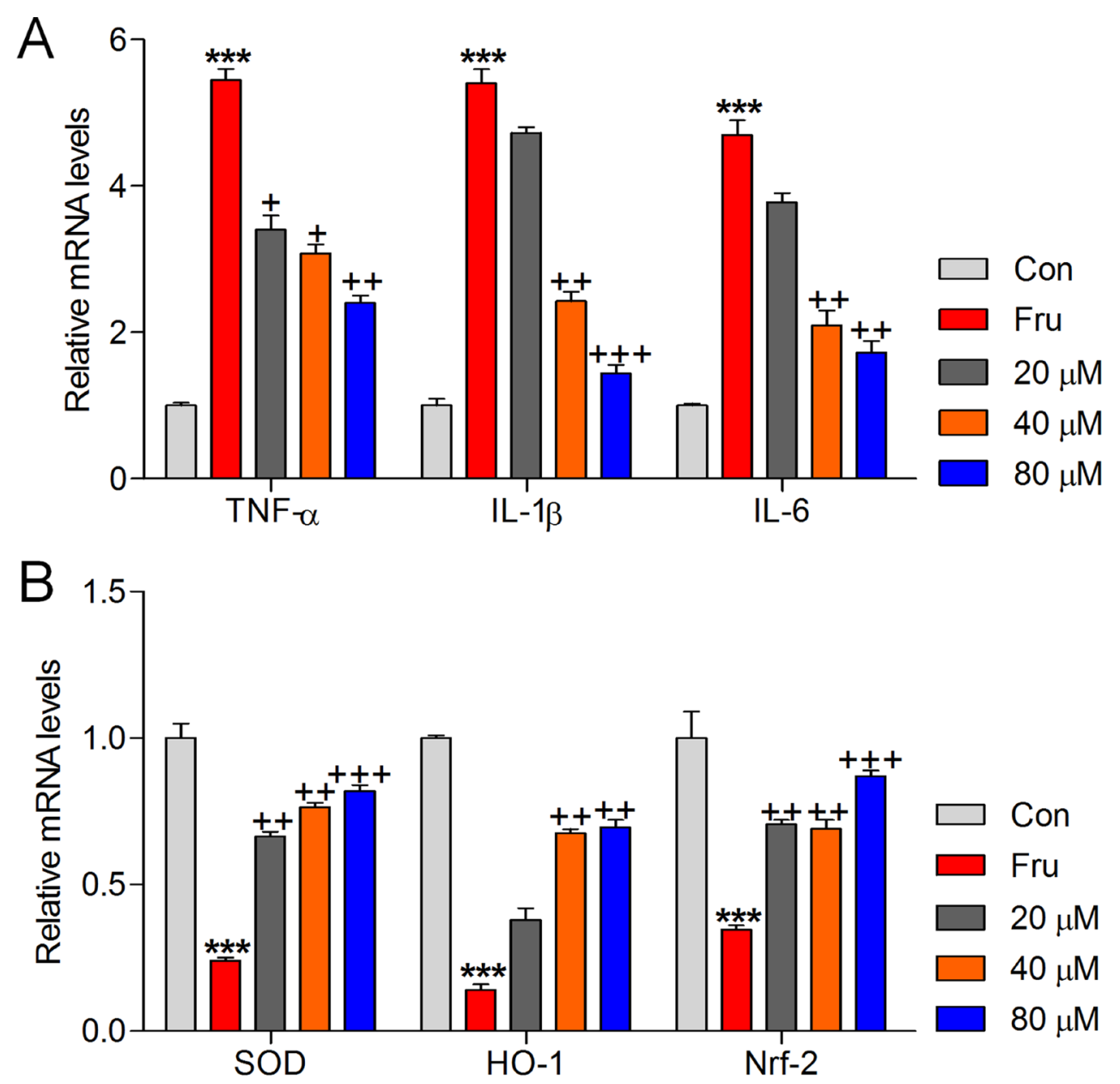

C

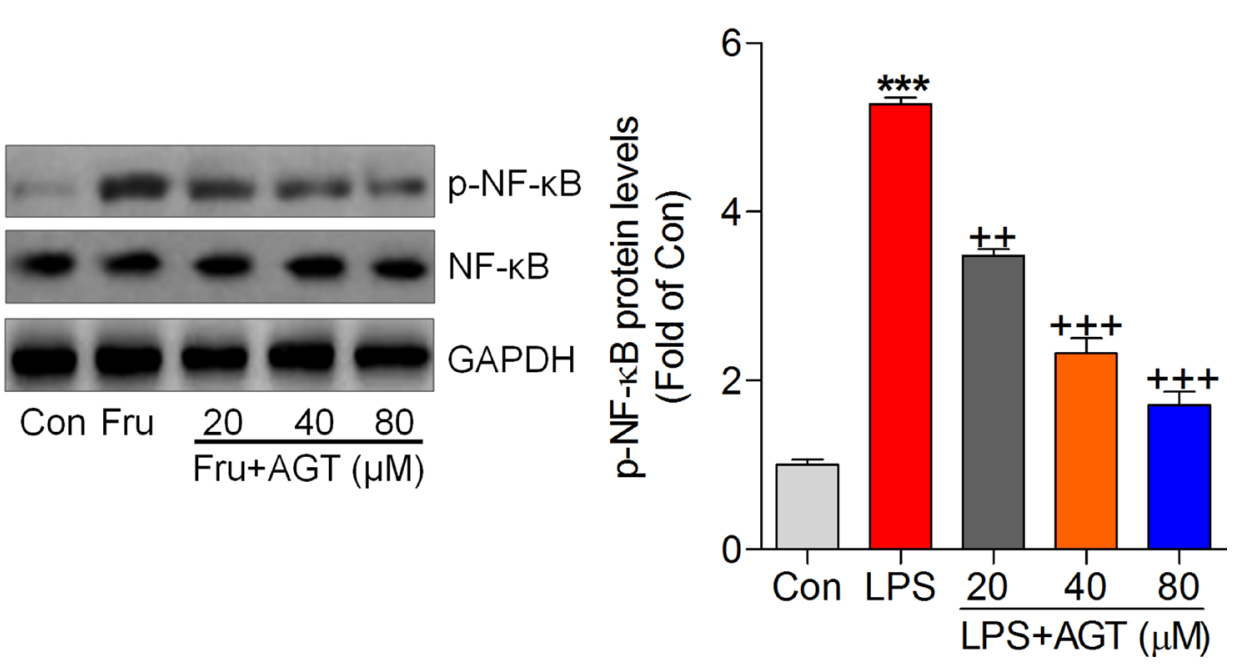

Figure 10: Apigetrin alleviates fructose-induced inflammation and oxidative stress in cells. NCM460 were incubated with $5 \mathrm{mM}$ fructose for $24 \mathrm{~h}$ with or without AGT at the indicated concentrations. (A) RT-qPCR analysis of TNF- $\alpha$, IL-1 $\beta$ and IL-6. (B) RTqPCR analysis of SOD, HO-1 and Nrf-2. (C) Western blot analysis of p-NF- $\kappa$ B. Data are represented as mean \pm S.E.M. ( $n=6-8 /$ group). ${ }^{* * *} P<0.001$ versus the Con group $;{ }^{+} P<0.05,{ }^{++} P<0.01$ and ${ }^{+++} P<0.001$ versus the LPS group. 
was recorded. At the end of the experiments, all mice were sacrificed after $12 \mathrm{~h}$ fasting. Eyeball blood was collected, and serum was obtained by centrifugation at $12,000 \mathrm{rpm}$ for $10 \mathrm{~min}$ at $4^{\circ} \mathrm{C}$ and stored at $-80^{\circ} \mathrm{C}$ for further analysis. The whole liver, visceral and subcutaneous fat, and intestine tissues were harvested and weighed on $4{ }^{\circ} \mathrm{C}$ glacial table, and either frozen in liquid nitrogen and kept at $-80^{\circ} \mathrm{C}$, or fixed in $4 \%$ paraformaldehyde for histological studies. The intestine length was also measured. The study was approved by the Ethics Committee on Animal Research at the Huai'an First People's Hospital, Nanjing Medical University (Huaian, China). The study protocol was approved by the Guide for the Care and Use of Laboratory Animals (The Ministry of Science and Technology of the People's Republic of China, 2006).

\section{Cells and culture}

The NCM460 cell line was purchased from the INCELL Corporation (San Antonio, USA). The cells were cultured in M3 media supplemented with 10\% FBS (fetal bovine serum), $100 \mathrm{U} / \mathrm{ml}$ penicillin and $100 \mu \mathrm{g} / \mathrm{ml}$ streptomycin. Cells were incubated at $37^{\circ} \mathrm{C}$ with $5 \% \mathrm{CO}_{2}$. Sub-confluent cells with exponential growth were applied in all experiments. $1 \times 10^{5}$ cells/well cells were seeded at in 6-well plates and treated with $50 \mathrm{ng} / \mathrm{ml}$ LPS or $5 \mathrm{mM}$ fructose in the presence or absence of 20, 40 and $80 \mu \mathrm{M}$ AGT for $24 \mathrm{~h}$. Then, all cells were harvested for further study.

\section{MTT analysis}

MTT was used to analyze the cell viability. Cells were treated with different concentrations $(0,2.5,5,10$, $20,40,80$ and $160 \mu \mathrm{M}$ ) of ALP for $24 \mathrm{~h}$ or $48 \mathrm{~h}$. Then, the culture medium was totally removed and $5 \mu \mathrm{MTT}$ solution $(10 \mathrm{mg} / \mathrm{ml})$ was added to $100 \mu$ of phenol redfree growth medium, and plates were cultured at $37^{\circ} \mathrm{C}$, $5 \% \mathrm{CO}_{2}$ cell culture environment for $4 \mathrm{~h}$. Mitochondrial decrease of MTT develops formazan crystals and dissolves in DMSO. Following, a micro-plate reader (BioRad, USA) was used to read the absorbance of each well at $540 \mathrm{~nm}$.

\section{Oral glucose tolerance test (OGTT) analysis}

Before sacrifice, OGTT was conducted. Mice were fasting for $6 \mathrm{~h}$. Then, all mice were treated with $20 \%$ glucose dissolved in saline orally. The tail-vein blood was collected at $-30,0,15,30,60,90$ and 120 min after glucose treatment, and the blood glucose levels were measured with o-toluidine reagent (Sigma).

\section{Flow cytometry analysis}

First, the intestinal epithelial and lamina propria cells were isolated. Intestines of mice were rinsed with cold phosphatebuffered saline (PBS), opened longitudinally, and cut into pieces of 1-cm lengths. Intestinal pieces were placed in ice-cold RPMI 1640 medium with 5\% fetal calf serum containing $1 \mathrm{mmol} / \mathrm{L}$ dithiothreitol. After vigorous shaking,

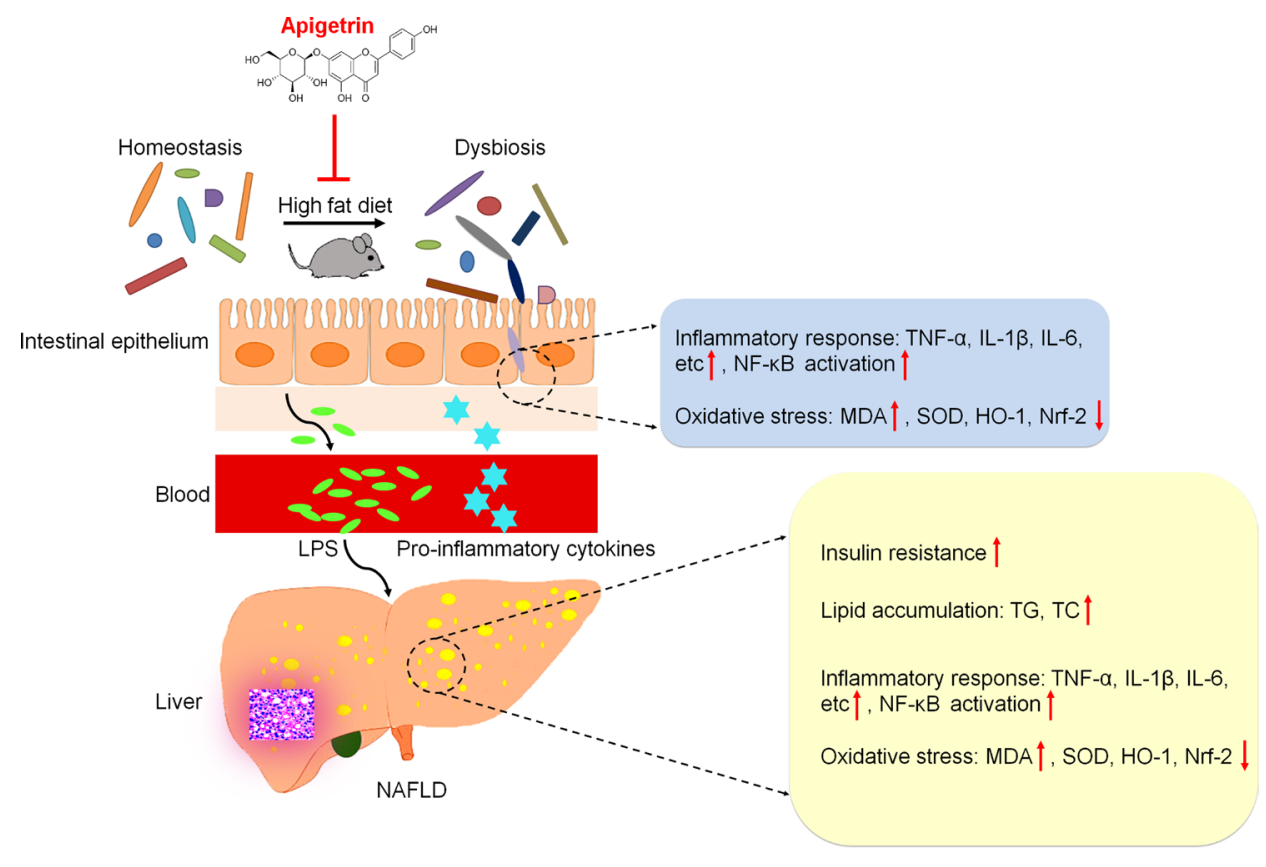

Figure 11: AGT administration prevents high fat diet-induced NAFLD in mice. High fat diet-induced bacterial overgrowth and impaired intestinal integrity, contributing to dysbiosis. Intestinal bacteria alterations leads to disruption of gut barrier integrity with the subsequent increase in gut permeability to bacteria-derived pathogens, including LPS. Intestinal injury was induced by high fat diet, along with inflammation and oxidative stress mice. In liver, high fat diet feeding resulted in insulin resistance, lipid accumulation, inflammatory response and oxidative stress through various signaling pathways, leading to NAFLD, which might be attributed to abnormal gut-liver axis. Significantly, high fat diet-caused NAFLD and intestine injury could be alleviated by apigetrin administration. 
the supernatant was discarded and tissue was incubated for 20 minutes in RPMI 1640 with 5\% fetal calf serum containing EDTA $(1 \mathrm{mmol} / \mathrm{L})$ at $37^{\circ} \mathrm{C}$ with shaking. This step was repeated for twice. Intestinal epithelial cells were collected from supernatant after the first incubation. For lamina propria cell isolation, tissue was further incubated in RPMI 1640 with 5\% fetal calf serum containing collagenase type VIII for 30 minutes at $37^{\circ} \mathrm{C}$ with shaking $(250 \mathrm{rpm})$. Cell suspension was sieved through a cell strainer $(100 \mu \mathrm{m})$. Lamina propria cells were collected by centrifugation. The cells were stained with PE-labeled TNF $\alpha$, PerCP-labeled CD11c, Pacific Blue-labeled CD11b, APC-labeled CD45.2, APC-labeled CD103, FITC-labeled Lys6C, or PECy7labeled F4/80 (all eBiosciences) and further analyzed by a flow cytometry (BD Pharmingen, USA).

\section{Assessment of biochemical indexes}

AST, ALT, TG, TC, SOD, GPx, and MDA were tested using biochemical kits following the manufacturer's instructions. The mouse insulin was measured using ELISA kits. Glucose was tested using a biochemical kit (Shanghai Bioleaf Biotech Co. Ltd, Shanghai, China). The levels of TNF- $\alpha$, IL-6, and IL-1 $\beta$ levels in serum from mice were determined by ELISA following the manufacturer's instructions. Plasma LPS level was calculated by a commercial ELISA kit (Cloud-Clone Corp, USA) based on the manufacturer's instruction.

\section{Western blot analysis}

Lysates from isolated sterile liver, intestine or intestinal epithelial cells, were separated using 10\% SDSPAGE and electro-transferred onto a PVDF. The PVDF with proteins were then blocked with 5\% skim fat dry milk in $0.1 \%$ Tween-20 in Tris-Buffered Saline (TBS) for $1.5 \mathrm{~h}$ to block the non-specific sites on blots. The primary antibodies dissolved in blocking buffer were used to determine the targeting protein blots at $4^{\circ} \mathrm{C}$ overnight. The bands on PVDF were covered by chemiluminescence with Pierce ECL Western Blotting Substrate reagents (Thermo Scientific Technology, USA). All experiments were carried out in triplicate and done three times independently.

\section{Real time-quantitative PCR (RT-qPCR) analysis}

Total RNA was isolated from the tissues and cells using TRIzol Reagent following the manufacturer's recommendations. $0.5 \mu \mathrm{g}$ RNA was reverse-transcribed using M-MLV reverse transcriptase. Single-stranded cDNA was amplified by PCR with primers (Shanghai Generay Biotech Co.,Ltd, Shanghai, China) specific to mouse TNF- $\alpha$, IL-1 $\beta$, IL-6, GLUT2, SOD, HO-1, Nrf2 and GAPDH used as a positive control. The primer sequences are shown in Table 1. To quantify the intestinal bacteria, DNA was extracted from adherent and luminal intestinal contents as described before [66]. DNA was amplified using published 16S rRNA primer sets for the universal bacteria and Sybr Green [67]. To determine the total bacterial load present in the cecum, the qPCR value for each sample was multiplied by the total amount of DNA per gram of cecal content. Firmicutes, Bacteroidetes, Lactobacillus and Akkermansia muciniphila were amplified using published primer sets and Sybr Green [6871]. The $16 \mathrm{~S}$ rRNA sequences were identified by locating the $16 \mathrm{~S}$ rRNA-targeting reverse and forward primers eub530F and eub1100aR targeting the V4-V6 regions.

\section{Immunofluorescent analysis}

For the immunofluorescence reaction, intestine cryosections were incubated with a blocking solution (0.01 mM PBS, pH 7.4) containing $5 \%$ bovine serum albumin (BSA) plus $0.1 \%$ Tween 20 for $1 \mathrm{~h}$ and, then, incubated overnight at $4^{\circ} \mathrm{C}$ with the p-NF- $\mathrm{B}$, SOD1, TNF- $\alpha$, and 4-HNE primary antibody (dilution 1:50 in PBS containing 3\% BSA). After washing with PBS, the intestine sections were incubated with the specific secondary antibody (dilution 1:100 in PBS containing $1 \%$ BSA solution) and DAPI (dilution 1:1000) for $2 \mathrm{~h}$ at room temperature. All sections were photographed by a digital camera equipped with an inverted fluorescence microscope. The cells after various treatments were rinsed with PBS twice. Then, the cells were fixed with $4 \%$ paraformaldehyde and washed with PBS solution. 5\% BSA was used to block the nonspecifc antigen binding sites and then all cells were incubated with anti-p-NF- $\mathrm{B}$ (dilution $1: 200)$ at $4^{\circ} \mathrm{C}$ overnight. On the following day, cells were rinsed with PBS solution and incubated with secondary antibody for $30 \mathrm{~min}$. And the nuclei were stained with 2-(4-amidinophenyl)-6-indolecarbamidine dihydrochloride (DAPI) (1:1000, KeyGene Biotech) for 5 min. All cells were finally observed using a fluorescence microscopy.

\section{Immunohistochemical analysis}

The liver, subcutaneous adipose tissue depots and ileal tissue were fixed in $4 \%$ paraformaldehyde for 24 $\mathrm{h}$ at room temperature. Samples were then immersed in ethanol $100 \%$ for $24 \mathrm{~h}$ before processing for paraffin embedding. Then, the conventional histological processing was performed, and then $4-\mu \mathrm{m}$-thick sections were cut for haematoxylin and eosin (H\&E) staining. The H\&E stained sections were imaged with a light microscope and scored by a blinded histopathologist according to the NAFLD activity score (NAS) system [72]. In order to visualize the neutral lipids, liver tissues were frozen in Tissue-TekO.C.T. compound and the sections were stained with oil-red O reagent (Sigma-Aldrich, USA) for 10 min following the manufacturer's recommendations. For measurement of length of villi, the number of goblet cells present on one villus was quantified and divided by the villus length. A minimum of 5 villi was analyzed in 
Table 1: Primer sequences of RT-qPCR test

\begin{tabular}{|c|c|c|}
\hline Gene & Forward primers $\left(5^{\prime}-3^{\prime}\right)$ & Reverse primers $\left(5^{\prime}-3^{\prime}\right)$ \\
\hline $\mathrm{mSOD}$ & GTGCTCATGGATGGCTTAGGAA & GAGTCACCACGTAAGATACAT \\
\hline mIL-1ß & TAACTGGAGCAGGTAGAGC & CAAGACACATATGCAGCGTA \\
\hline mTNF- $\alpha$ & GCCGAACGCAATCCGACAA & CAGGATCCCACAGGCGTGCA \\
\hline mGLUT2 & CCAGGAAGAAGGCTGCAAT & CCAGTTACGTCTGACGTTGTA \\
\hline mHO-1 & CACAGTCAACAGACAGATCG & AGCCAGTTCTCCGAGATGTGA \\
\hline $\mathrm{mNrf}-2$ & TCAGGATCAGCCAGGGGTC & ACATCACСТCTCTATCAACAG \\
\hline mGAPDH & TTAACATACGAGGAGAGCAG & AATGAGTTCCTCGACACCTCACC \\
\hline
\end{tabular}

each mouse through a blinded manner. Paraffin-embedded liver tissue sections were cut $(4 \mu \mathrm{m})$ and stained for SOD1, TNF- $\alpha$, and 4-HNE, respectively, using primary antibodies (1:200) as described previously [73, 74]. Using an image acquisition and analysis system incorporated in the microscope.

\section{Statistical analysis}

Data are expressed as mean \pm SEM. Statistical analysis was performed using one-way analysis of variance (ANOVA) with a post hoc Bonferroni multiple comparison test (GraphPad, USA). All results were considered statistically significant at $p<0.05$.

\section{CONFLICTS OF INTEREST}

None.

\section{REFERENCES}

1. Roberto CA, Swinburn B, Hawkes C, Huang TT, Costa SA, Ashe M, Zwicker L, Cawley JH, Brownell KD. Patchy progress on obesity prevention: emerging examples, entrenched barriers, and new thinking. Lancet. 2015; 385:2400-2409.

2. Furukawa S, Fujita T, Shimabukuro M, Iwaki M, Yamada Y, Nakajima Y, Nakayama O, Makishima M, Matsuda M, Shimomura I. Increased oxidative stress in obesity and its impact on metabolic syndrome. J Clin Invest. 2004; 114:1752-1761.

3. Esser N, Legrand-Poels S, Piette J, Scheen AJ, Paquot $\mathrm{N}$. Inflammation as a link between obesity, metabolic syndrome and type 2 diabetes. Diabetes Res Clin Pr. 2014; 105:141-150.

4. Estep JM, Goodman Z, Sharma H, Younossi E, Elarainy $\mathrm{H}$, Baranova A, Younossi Z. Adipocytokine expression associated with miRNA regulation and diagnosis of NASH in obese patients with NAFLD. Liver Int. 2015; 35:1367-1372.

5. Amri R, Bordeianou LG, Sylla P, Berger DL. Obesity, outcomes and quality of care: body mass index increases the risk of wound-related complications in colon cancer surgery. Am J Surg. 2014; 207:17-23.
6. Weindruch $\mathrm{R}$. The retardation of aging by caloric restriction:studies in rodents and primates. Toxicol Pathol, 1996; 24:742-745.

7. Timmers S, Konings E, Bilet L, van de Weijer T, Goossens GH, Hoeks J, van der Krieken S, Ryu D, Kersten S, Moonen-Kornips E, Hesselink MKC, Kunz I, SchrauwenHinderling VB, Blaak E, Auwerx J, Schrauwen P. Calorie restriction-like effects of 30 days of resveratrol supplementation on energy metabolism and metabolic profile in obese humans. Cell Metab. 2011; 14:612-622.

8. Martins C, Kulseng B, King NA, Holst JJ, Blundell JE. The effects of exercise-induced weight loss on appetite-related peptides and motivation to eat. J Clin Endocr Metab. 2010; 95:1609-1616.

9. Crujeiras AB, Carreira MC, Cabia B, Andrade S, Amil M, Casanueva FF. Leptin resistance in obesity:an epigenetic landscape. Life Sci. 2015; 140:57-63.

10. Markwald RR, Melanson EL, Smith MR, Higgins J, Perreault L, Eckel RH, Wright KP Jr. Impact of insufficient sleep on total daily energy expenditure, food intake, and weight gain. P Natl Acad Sci. 2013; 110:5695-5700.

11. Chaung K, Li J, Ha NB, Do ST, Tran P, Nguyen HA, Nguyen KK, Garcia RT, Nguyen MH. Sa1491-Similar Rates of Complete Viral Suppression (CVS) and Biochemical Response (BR) in Chronic Hepatitis B (CHB) Patients with and Without Nonalcoholic Fatty Liver Disease (NAFLD) and Metabolic Syndrome (MS). Gastroenterology. 2017; 152:S1086.

12. LaBrecque DR, Abbas $Z$, Anania F, Ferenci $P$, Khan AG, Goh KL, Hamid SS, Isakov V, Lizarzabal M, Peñaranda MM, Ramos JF, Sarin S, Stimac D, Thomson AB, Umar M, Krabshuis J, LeMair A. World Gastroenterology Organisation global guidelines:Nonalcoholic fatty liver disease and nonalcoholic steatohepatitis. J Clin Gastroenterol. 2014; 48:467-473.

13. Marí M, Morales A, Colell A, et al. Oxidative stress in nonalcoholic fatty liver disease//Studies on Hepatic Disorders. Springer International Publishing. 2015; 279 308.

14. Gomez-Quiroz LE, Seo D, Lee YH, Kitade M, Gaiser T, Gillen M, Lee SB, Gutierrez-Ruiz MC, Conner EA, Factor VM, Thorgeirsson SS, Marquardt JU. Loss of c-Met signaling sensitizes hepatocytes to lipotoxicity and induces 
cholestatic liver damage by aggravating oxidative stress. Toxicology. 2016; 361:39-48.

15. Al Rifai M, Silverman MG, Nasir K, Budoff MJ, Blankstein R, Szklo M, Katz R, Blumenthal RS, Blaha MJ. The association of nonalcoholic fatty liver disease, obesity, and metabolic syndrome, with systemic inflammation and subclinical atherosclerosis:the Multi-Ethnic Study of Atherosclerosis (MESA). Atherosclerosis. 2015; 239:629-633.

16. Luft VC, Schmidt MI, Pankow JS, Couper D, Ballantyne CM, Young JH, Duncan BB. Chronic inflammation role in the obesity-diabetes association: a case-cohort study. Diabetol Metab Syndr. 2013; 5:31.

17. Everard A, Belzer C, Geurts L, Ouwerkerk JP, Druart C, Bindels LB, Guiot Y, Derrien M, Muccioli GG, Delzenne NM, de Vos WM, Cani PD. Cross-talk between Akkermansia muciniphila and intestinal epithelium controls diet-induced obesity. P Natl Acad Sci. 2013; 110:9066-9071.

18. Mowat AM, Agace WW. Regional specialization within the intestinal immune system. Nature reviews. Immunology. 2014; $14: 667$.

19. Shen W, Gaskins HR, McIntosh MK. Influence of dietary fat on intestinal microbes, inflammation, barrier function and metabolic outcomes. J Nutr Biochem. 2014; 25:270 280.

20. Tang WHW, Wang Z, Levison BS, Koeth RA, Britt EB, $\mathrm{Fu} \mathrm{X}, \mathrm{Wu} \mathrm{Y}$, Hazen SL. Intestinal microbial metabolism of phosphatidylcholine and cardiovascular risk. New Engl J Med. 2013; 368:1575-1584.

21. Rosenbaum M, Knight R, Leibel RL. The gut microbiota in human energy homeostasis and obesity. Trends Endocrin Met. 2015; 26:493-501.

22. Henao-Mejia J, Elinav E, Thaiss CA, Flavell RA. Inflammasomes and metabolic disease. Annu Rev Physiol. 2014; 76:57-78.

23. Ceccarelli S, Panera N, De Stefanis C, Gnani D, Crudele A, Rychlicki C, Petrini S, Mina M, Furlanello C, De Minicis S, Svegliati-Baroni G, Nobili V, Alisi A. P280 lps-induced transcription factors involved in non-alcoholic liver disease (nafld) inflammatory and pro-fibrogenic pattern. J Hepatol. 2014; 60: S159.

24. Daniel H, Gholami AM, Berry D, Desmarchelier C, Hahne H, Loh G, Mondot S, Lepage P, Rothballer M, Walker A, Böhm C, Wenning M, Wagner M, Blaut M, SchmittKopplin P, Kuster B, Haller D, Clavel T. High-fat diet alters gut microbiota physiology in mice. ISME J. 2014; 8:295.

25. Solanki I, Parihar P, Mansuri ML, Parihar MS. Flavonoid-based therapies in the early management of neurodegenerative diseases. Adv Nutr. 2015; 6:64-72.

26. Feliciano RP, Pritzel S, Heiss C, Rodriguez-Mateos A. Flavonoid intake and cardiovascular disease risk. Curr Opin Food Sci. 2015; 2:92-99.

27. Smith AJ, Oertle J, Warren D, Prato D. Quercetin:A promising flavonoid with a dynamic ability to treat various diseases, infections, and cancers. J Cancer Ther. 2016; 7:83.
28. Lim HS, Kim OS, Kim BY, Jeong SJ. Apigetrin from Scutellaria baicalensis Georgi Inhibits Neuroinflammation in BV-2 Microglia and Exerts Neuroprotective Effect in HT22 Hippocampal Cells. J Med Food. 2016; 19:10321040.

29. Lin XH, Pan JB, Zhang XJ. Anti-inflammatory and antioxidant effects of apigetrin on LPS-induced acute lung injury by regulating Nrf2 and AMPK pathways. Biochem Bioph Res Co. 2017.

30. Tsolmon S, Nakazaki E, Han J, Isoda H. Apigetrin induces erythroid differentiation of human leukemia cells K562: proteomics approach. Mol Nutr Food Res. 2011; 55.

31. Andringa KK, Udoh US, Landar A, Bailey SM. Proteomic analysis of 4-hydroxynonenal (4-HNE) modified proteins in liver mitochondria from chronic ethanol-fed rats. Redox Bio. 2014; 2:1038-1047.

32. Mehal WZ. The Gordian Knot of dysbiosis, obesity and NAFLD. Nat Rev Gastro Hepat. 2013; 10:637-644.

33. Zhao L. The gut microbiota and obesity:from correlation to causality. Nat Rev Microbiol. 2013; 11:639.

34. Röder PV, Geillinger KE, Zietek TS, Thorens B, Koepsell H, Daniel H. The role of SGLT1 and GLUT2 in intestinal glucose transport and sensing. PloS one. 2014; 9:e89977.

35. Blanco AM, Bertucci JI, Ramesh N, Delgado MJ, Valenciano AI, Unniappan S. Ghrelin Facilitates GLUT2-, SGLT1-and SGLT2-mediated Intestinal Glucose Transport in Goldfish (Carassius auratus). Sci Rep. 2017; 7:45024.

36. Alam MA, Subhan N, Rahman MM, Uddin SJ, Reza HM, Sarker SD. Effect of citrus flavonoids, naringin and naringenin, on metabolic syndrome and their mechanisms of action. Adv Nutr. 2014; 5:404-417.

37. Goto T, Kim YI, Takahashi N, Kawada T. Natural compounds regulate energy metabolism by the modulating the activity of lipid-sensing nuclear receptors. Mol Nutr Food Res. 2013; 57:20-33.

38. Ohashi K, Shibata R, Murohara T, Ouchi N. Role of antiinflammatory adipokines in obesity-related diseases. Trends Endocrin Met. 2014; 25:348-355.

39. Koo SH. Nonalcoholic fatty liver disease:molecular mechanisms for the hepatic steatosis. Clin Mol Hepatol. 2013; 19:210.

40. Gaggini M, Morelli M, Buzzigoli E, DeFronzo RA, Bugianesi E, Gastaldelli A. Non-alcoholic fatty liver disease (NAFLD) and its connection with insulin resistance, dyslipidemia, atherosclerosis and coronary heart disease. Nutrients. 2013; 5:1544-1560.

41. Fetoni AR, Paciello F, Rolesi R, Eramo SL, Mancuso C, Troiani D, Paludetti G. Rosmarinic acid up-regulates the noise-activated Nrf2/HO-1 pathway and protects against noise-induced injury in rat cochlea. Free Radical Bio Med. 2015; 85:269-281.

42. Leung WS, Yang ML, Lee SS, Kuo CW, Ho YC, HuangLiu R, Lin HW, Kuan YH. Protective effect of zerumbone reduces lipopolysaccharide-induced acute lung injury 
via antioxidative enzymes and $\mathrm{Nrf} 2 / \mathrm{HO}-1$ pathway. Int Immunopharmacol. 2017; 46:194-200.

43. Li P, Su L, Li X, Di W, Zhang X, Zhang C, He T, Zhu X, Zhang Y, Li Y. Remote limb ischemic postconditioning protects mouse brain against cerebral ischemia/reperfusion injury via upregulating expression of Nrf2, HO-1 and NQO1 in mice. Int J Neurosc. 2016; 126:552-559.

44. Kook SH, Kim KA, Ji H, Lee D, Lee JC. Irradiation inhibits the maturation and mineralization of osteoblasts via the activation of Nrf2/HO-1 pathway. Mol Cell Biochem. 2015; 410:255-266.

45. Loboda A, Damulewicz M, Pyza E, Jozkowicz A, Dulak J. Role of Nrf2/HO-1 system in development, oxidative stress response and diseases:an evolutionarily conserved mechanism. Cell Mol Life Sci. 2016; 73:3221-3247.

46. Chen L, Wang L, Zhang X, Cui L, Xing Y, Dong L, Liu Z, Li Y, Zhang X, Wang C, Bai X, Zhang J, Zhang L, Zhao X. The protection by octreotide against experimental ischemic stroke:up-regulated transcription factor Nrf2, HO-1 and down-regulated NF- $\kappa \mathrm{B}$ expression. Brain Res. 2012, 1475:80-87.

47. Zhong X, Li X, Liu F, Shang D. Omentin inhibits TNF$\alpha$-induced expression of adhesion molecules in endothelial cells via ERK/NF- $\kappa \mathrm{B}$ pathway. Biochem Bioph Res Co. 2012; 425:401-406.

48. Shimada H, Rajagopalan LE. Rho kinase-2 activation in human endothelial cells drives lysophosphatidic acidmediated expression of cell adhesion molecules via NF- $\mathrm{KB}$ p65. J Biol Chem. 2010; 285:12536-12542.

49. Ali S, Mohs A, Thomas M, Klare J, Ross R, Schmitz ML, Martin MU. The dual function cytokine IL-33 interacts with the transcription factor NF- $\mathrm{BB}$ to dampen NF- $\mathrm{NB}-$ stimulated gene transcription. J Immunol 2011; 187:16091616.

50. Hegazy SK, El-Bedewy MM. Effect of probiotics on proinflammatory cytokines and NF- $\mathrm{\kappa B}$ activation in ulcerative colitis. World J Gastroentero. 2010; 16:4145.

51. Donath MY, Shoelson SE. Type 2 diabetes as an inflammatory disease. Nat Rev Immunol. 2011; 11:98.

52. Sommer F, Bäckhed F. The gut microbiota--masters of host development and physiology. Nat Rev Microbiol. 2013; 11:227.

53. Sekirov I, Russell SL, Antunes LCM, Finlay BB. Gut microbiota in health and disease. Physiol Rev. 2010; 90:859-904.

54. Kim KA, Gu W, Lee IA, Joh EH, Kim DH. High fat dietinduced gut microbiota exacerbates inflammation and obesity in mice via the TLR4 signaling pathway. PloS one. 2012; 7:e47713.

55. Ding S, Chi MM, Scull BP, Rigby R, Schwerbrock NM, Magness S, Jobin C, Lund PK. High-fat diet:bacteria interactions promote intestinal inflammation which precedes and correlates with obesity and insulin resistance in mouse. PloS one. 2010; 5:e12191.
56. Conterno L, Fava F, Viola R, Tuohy KM. Obesity and the gut microbiota:does up-regulating colonic fermentation protect against obesity and metabolic disease?. Genes Nutr. $2011 ; 6: 241-260$.

57. Wang Y, Tu Q, Yan W, Xiao D, Zeng Z, Ouyang Y, Huang L, Cai J, Zeng X, Chen Y, Liu A. CXC195 suppresses proliferation and inflammatory response in LPS-induced human hepatocellular carcinoma cells via regulating TLR4MyD88-TAK1-mediated NF-kB and MAPK pathway. Biochem Bioph Res Co. 2015; 456:373-379.

58. Conterno L, Fava F, Viola R, Tuohy KM. Obesity and the gut microbiota:does up-regulating colonic fermentation protect against obesity and metabolic disease?. Genes Nutr. $2011 ; 6: 241-260$.

59. Brahe LK, Astrup A, Larsen LH. Is butyrate the link between diet, intestinal microbiota and obesity-related metabolic diseases?. Obes Rev. 2013; 14:950-959.

60. Shen J, Obin MS, Zhao L. The gut microbiota, obesity and insulin resistance. Mol Aspects Med. 2013; 34:39-58.

61. Larsen N, Vogensen FK, van den Berg FWJ, Nielsen DS, Andreasen AS, Pedersen BK, Al-Soud WA, Sørensen SJ, Hansen LH, Jakobsen M. Gut microbiota in human adults with type 2 diabetes differs from non-diabetic adults. PloS one. 2010; 5: e9085.

62. de La Serre CB, Ellis CL, Lee J, Hartman AL, Rutledge JC, Raybould HE. Propensity to high-fat diet-induced obesity in rats is associated with changes in the gut microbiota and gut inflammation. Am J Physiol-Gastr L. 2010; 299: G440-G448.

63. Everard A, Belzer C, Geurts L, Ouwerkerk JP, Druart C, Bindels LB, Guiot Y, Derrien M, Muccioli GG, Delzenne NM, de Vos WM, Cani PD. Cross-talk between Akkermansia muciniphila and intestinal epithelium controls diet-induced obesity. P Natl Acad Sci. 2013; 110:9066-9071.

64. Shin NR, Lee JC, Lee HY, Kim MS, Whon TW, Lee MS, Bae JW. An increase in the Akkermansia spp. population induced by metformin treatment improves glucose homeostasis in diet-induced obese mice. Gut. 2013; gutjnl-2012-303839.

65. Tremaroli V, Bäckhed F. Functional interactions between the gut microbiota and host metabolism. Nature. 2012; 489:242.

66. Hartmann P, Chen P, Wang HJ, Wang L, McCole DF, Brandl K, Stärkel P, Belzer C, Hellerbrand C, Tsukamoto H, Ho $\mathrm{SB}$, Schnabl B. Deficiency of intestinal mucin-2 ameliorates experimental alcoholic liver disease in mice. Hepatology. 2013; 58:108-119.

67. Horz HP, Vianna ME, Gomes B, Conrads G. Evaluation of universal probes and primer sets for assessing total bacterial load in clinical samples:general implications and practical use in endodontic antimicrobial therapy. J Clin Microbiol. 2005; 43:5332-5337.

68. Collado MC, Derrien M, Isolauri E, de Vos WM, Salminen S. Intestinal integrity and Akkermansia muciniphila, a 
mucin-degrading member of the intestinal microbiota present in infants, adults, and the elderly. Appl Environ Microb. 2007; 73:7767-7770.

69. Guo X, Xia X, Tang R, Zhao H, Wang K. Development of a real-time PCR method for Firmicutes and Bacteroidetes in faeces and its application to quantify intestinal population of obese and lean pigs. Lett Appl Microbiol. 2008; 47:367373.

70. Nakanishi Y, Murashima K, Ohara H, Suzuki T, Hayashi H, Sakamoto M, Fukasawa T, Kubota H, Hosono A, Kono T, Kaminogawa S, Benno Y. Increase in terminal restriction fragments of Bacteroidetes-derived 16S rRNA genes after administration of short-chain fructooligosaccharides. Appl Environ Microb. 2006; 72:6271-6276.

71. Rinttilä T, Kassinen A, Malinen E, Krogius L, Palva A. Development of an extensive set of 16S rDNA-targeted primers for quantification of pathogenic and indigenous bacteria in faecal samples by real-time PCR. J Appl Microbiol. 2004; 97:1166-1177.
72. Kleiner DE, Brunt EM, Van Natta M, Behling C, Contos MJ, Cummings OW, Ferrell LD, Liu YC, Torbenson MS, Unalp-Arida A, Yeh M, McCullough AJ, Sanyal AJ. Design and validation of a histological scoring system for nonalcoholic fatty liver disease. Hepatology. 2005; 41:1313-1321.

73. Bergheim I, Weber S, Vos M, Kramer S, Volynets V, Kaserouni S, McClain CJ, Bischoff SC. Antibiotics protect against fructose-induced hepatic lipid accumulation in mice: role of endotoxin. J Hepatol. 2008; 48:983-992.

74. Spruss A, Kanuri G, Stahl C, Bischoff SC, Bergheim I. Metformin protects against the development of fructoseinduced steatosis in mice: role of the intestinal barrier function. Lab Invest. 2012; 92:1020-1032. 